\title{
Imaging Reactive Oxygen Species-Induced Modifications in Living Systems
}

\author{
Giuseppe Maulucci, ${ }^{1}$ Goran Bačić, Lori Bridal, ${ }^{3}$ Harald H.H.W. Schmidt, \\ Bertrand Tavitian, Thomas Viel, ${ }^{5}$ Hideo Utsumi, ${ }^{6}$ A. Süha Yalçın, and Marco De Spirito ${ }^{1}$
}

\begin{abstract}
Significance: Reactive Oxygen Species (ROS) may regulate signaling, ion channels, transcription factors, and biosynthetic processes. ROS-related diseases can be due to either a shortage or an excess of ROS. Recent Advances: Since the biological activity of ROS depends on not only concentration but also spatiotemporal distribution, real-time imaging of ROS, possibly in vivo, has become a need for scientists, with potential for clinical translation. New imaging techniques as well as new contrast agents in clinically established modalities were developed in the previous decade. Critical Issues: An ideal imaging technique should determine ROS changes with high spatio-temporal resolution, detect physiologically relevant variations in ROS concentration, and provide specificity toward different redox couples. Furthermore, for in vivo applications, bioavailability of sensors, tissue penetration, and a high signalto-noise ratio are additional requirements to be satisfied. Future Directions: None of the presented techniques fulfill all requirements for clinical translation. The obvious way forward is to incorporate anatomical and functional imaging into a common hybrid-imaging platform. Antioxid. Redox Signal. 24, 939-958.
\end{abstract}

\section{Introduction}

$\mathbf{R}$ EACTIVE OXYGEN SPECIES (ROS) such as superoxide, hydrogen peroxide, and peroxynitrite are highly reactive in terms of oxidative modifications of biomacromolecules. Exogenous ROS can be produced from pollutants, tobacco, smoke, drugs, xenobiotics, or radiation; whereas endogenous ROS are produced intracellularly through multiple mechanisms. Depending on the cell and tissue types, the major sources are NADPH oxidase (NOX) complexes (seven distinct isoforms) in cell membranes, mitochondria, peroxisomes, and endoplasmic reticulum (30).

Mitochondria produce superoxide radical $\left(\mathrm{O}_{2}{ }^{-}\right)$when oxygen is prematurely and incompletely reduced. Superoxide can initiate lipid peroxidation in its protonated form, hydroperoxyl $\mathrm{HO}_{2} \cdot$, and can be converted to hydrogen peroxide $\left(\mathrm{H}_{2} \mathrm{O}_{2}\right)$. Myeloperoxidase (MPO), which is released from cytoplasmic granules of activated phagocytes by a degranulation process, reacts with $\mathrm{H}_{2} \mathrm{O}_{2}$ and chloride ions to generate hypochlorous acid/hypochlorite ( $\mathrm{HOCl} / \mathrm{OCl}(-))$. $\mathrm{HOCl}$, a strong oxidant, in turn, reacts with proteins to form $\mathrm{HOCl}$-modified proteins. Reactive nitrogen species (RNS) are derived from nitric oxide $\left(\mathrm{NO}^{\bullet}\right)$ and superoxide $\left(\mathrm{O}_{2}{ }^{--}\right)$via the enzymatic activity of inducible nitric oxide synthase (NOS) and NOX, respectively. The reaction of nitric oxide $\left(\mathrm{NO}^{\bullet}\right)$ with superoxide $\left(\mathrm{O}_{2}{ }^{-}\right)$ leads to the formation of peroxynitrite $\left(\mathrm{ONOO}^{-}\right)$(Fig. 1) (30).

These reactive species are essential regulators of several physiological processes, ranging from intermediary metabolism

\footnotetext{
${ }^{1}$ Institute of Physics, Catholic University of Sacred Heart, Roma, Italy.

${ }^{2}$ Faculty of Physical Chemistry, University of Belgrade, Belgrade, Serbia.

${ }^{3}$ Laboratoire d'Imagerie Biomédicale, Sorbonne Universités and UPMC Univ Paris 06 and CNRS and INSERM, Paris, France.

${ }^{4}$ Department of Pharmacology and Personalised Medicine, CARIM, Faculty of Health, Medicine \& Life Science, Maastricht University, Maastricht, the Netherlands.

${ }^{5}$ Laboratoire de Recherche en Imagerie, Université Paris Descartes, Hôpital Européen Georges Pompidou, Service de Radiologie, Paris, France.

${ }^{6}$ Innovation Center for Medical Redox Navigation, Kyushu University, Fukuoka, Japan.

${ }^{7}$ Department of Biochemistry, School of Medicine, Marmara University, İstanbul, Turkey.

(C) Giuseppe Maulucci et al. 2016; Published by Mary Ann Liebert, Inc. This Open Access article is distributed under the terms of the Creative Commons License (http://creativecommons.org/licenses/by/4.0), which permits unrestricted use, distribution, and reproduction in any medium, provided the original work is properly credited.
} 


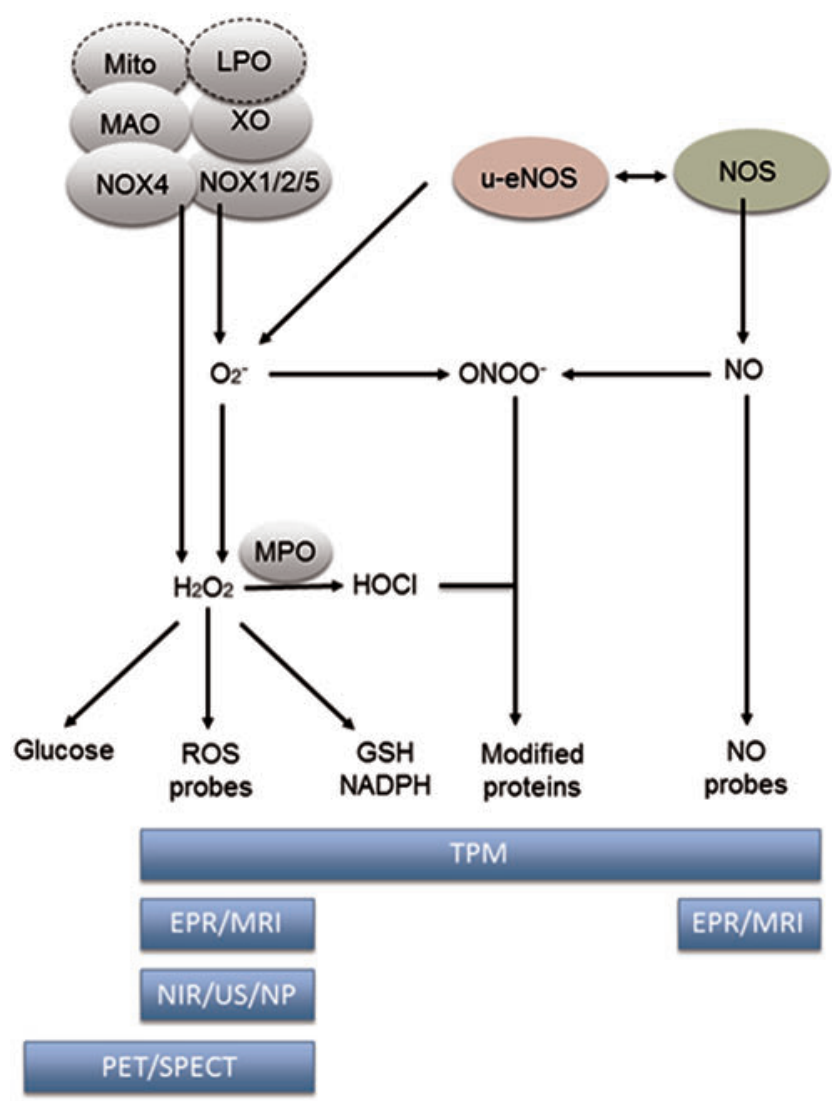

FIG. 1. Spectrum of different ROS imaging techniques. In the upper part, different sources of ROS are shown: Mitochondria (mito), lipid peroxides (LPO), monoamine oxidase (MAO), nicotinamide adenine dinucleotide phosphate oxidase (NOX4 and NOX 1/2/5), xanthine oxidase (XO), and nitric oxide synthases (NOS and e-NOS). These result in different types of ROS [including superoxide radical $\left(\mathrm{O}_{2}{ }^{--}\right)$, hydrogen peroxide $\left(\mathrm{H}_{2} \mathrm{O}_{2}\right)$, hypoclorous acid $(\mathrm{HOCl})$, peroxynitrite radical $\left(\mathrm{ONOO}^{-}\right)$, nitric oxide(NO)] and ROSinduced modifications of GSH, NADPH, proteins, or glucose uptake, which, in turn, are detected by different imaging technologies (for abbreviations and details, see text). ROS, reactive oxygen species. To see this illustration in color, the reader is referred to the web version of this article at www.liebertpub.com/ars

to the inflammatory response. Their altered spatiotemporal distribution plays a central role in the physiopathology of disease (21).

An understanding of the complexity of ROS signaling requires the determination of their spatiotemporal distribution with high resolution, specificity, and sensitivity. Toward this aim, significant progress in ROS imaging at the level of intact cells, tissues and whole organs, as well as living organisms was achieved in the previous decade. Among these advancements, an important role was played by the development of novel synthetic or genetically encoded fluorescent ROS indicators and in vivo imaging technologies $(17,91,96$, 123, 127, 145).

In particular, the possibility of detecting ROS dynamics in vivo has stimulated research in medical imaging with the aim of providing new information that will be beneficial for disease management. This area of medical imaging research covers a wide domain of different imaging modalities, each with its own sensitivity and resolution. Modalities include Magnetic Resonance Imaging (MRI), Ultrasound (US), Positron Emission Tomography (PET), Single-Photon Emission Computed Tomography (SPECT), and other optical imaging methods $(2,51,103,108,109,138)$ (Fig. 1). In this context, improvements in detection efficiency as well as new contrast agents for these well-established modalities were developed in the previous decade. However, low levels of intracellular ROS require new and more sensitive methods. Here, we will review the methods emerging to image the complexity of the ROS dynamics in vivo with a focus on those that have potential for clinical application.

\section{Redox-Sensitive Two-Photon Microscopy}

Two-photon microscopy (TPM) is a well-established submicron resolution imaging technique that is characterized by low phototoxicity and deep tissue penetration. In the twophoton process, the probe absorbs two photons whose individual energy is only half of the energy needed to excite that molecule (109). TPM excitation via near infrared (NIR) laser light reduces tissue and water absorption. Penetration depths can reach $1 \mathrm{~mm}$ into biological tissues, and the reduction of photo-bleaching, photo-damage, and phototoxicity is achieved by the spatial confinement of excitation (109). With these advantages, TPM has yielded novel and unique structural and functional information on cells and tissues.

In this context, determination of the spatial distribution of redox-active compounds and their time evolution is an important issue to be addressed, since redox homeostasis, playing a crucial role in many pathologies, can be a decisive target for pharmaceutical intervention (30).

Several fluorescence approaches to image ROS and redox potentials with high resolution have been attempted to address this task. Two of them are the most promising: Twophoton Fluorescence Ratio Imaging Microscopy (TP-FRIM) and Two Photon Fluorescence Lifetime Imaging Microscopy (TP-FLIM) $(94,137,143)$. These techniques have allowed a quantification of specific concentrations of intracellular redox species by canceling out the possible perturbations due to instrument efficiency and dye concentration.

In TP-FRIM, the absorption or emission spectrum is differently sensitive to the redox state of the compound. One wavelength range of the emission or excitation spectrum may be less sensitive, or sensitive in the opposite direction with respect to another selected range. Because absorption or emission originates from the same volume, the ratio of fluorescence measured in the two ranges is independent of optical path length, probe concentration, and excitation intensity.

TP-FLIM allows for the detection of the redox state of compounds by measuring differences in the exponential decay rate of the fluorescence (lifetime) of the probe by singlewavelength excitation. A quantitative determination of the redox state independent of probe concentration could be obtained.

\section{Two-photon redox-sensitive probes}

Determination of the spatial distribution of different redoxactive compounds ( $\mathrm{GSH}, \mathrm{NAD}(\mathrm{P}) \mathrm{H}, \mathrm{H}_{2} \mathrm{O}_{2}$, NO etc.) is an important aim for diagnosis and treatment. Although a number of probes that are able to detect fluorescence in cultured cells are available, recent efforts have aimed at developing specific and highly sensitive TP-FRIM and TP-FLIM-based probes to 
improve a quantitative analysis of ROS in deep tissue and for intra-vital microscopy $(17,19,27,79,126,145)$.

\section{Two-photon sensitive probes for assessment of glutathione redox state}

The redox state of the reduced and oxidized glutathione couple (GSH:GSSG), the most abundant redox couple in a cell, is an informative readout of the cellular redox environment (30). Glutathione-specific, redox-sensitive variants of the Yellow Fluorescent Protein (rxYFP) and the Green Fluorescent Protein (roGFP1 and roGFP2) allowed FRIM real-time monitoring in the intracellular GSH:GSSG redox ratio (92-94, 123). The specificity of these probes for glutathione was enhanced by linking them to human glutaredoxin 1 (Grx1) (12). To extend in vivo use of these probes, Wolf et al. (145) generated transgenic mice expressing roGFP in several tissues to ratiometrically monitor oxidative stress in skin epidermal keratinocytes. However, visible excitation and emission light do not permit a deeper penetration in tissues. As a result, measurement of the cellular glutathione redox potential (EG) is affected by non-negligible systematic errors (95). Furthermore, these redox probes, when linked to enzymatically active redox proteins (i.e., Grx1), may alter cellular redox homeostasis. Guzman and coworkers reported measurements of mitochondrial oxidative stress on dopaminergic neurons in transgenic mice expressing mito-roGFP, an roGFP that selectively tags targeted to mitochondria, with TPM (42). However, the suitability of this probe for potential TP-FRIM application has yet to be tested. To overcome these issues, several GSH-sensitive, TP-excitable, nonencoded chemoselective probes were engineered for in vivo applications (79). However, even in these cases, TP-FRIM/TP-FLIM potentials have yet to be characterized. Besides all these profuse efforts, further improvements in the development of glutathionespecific redox probes are still needed.

\section{Two-photon NADPH redox state sensitive probes}

The intracellular metabolic substrates NADH and NADPH $(\mathrm{NAD}(\mathrm{P}) \mathrm{H})$ have been used as intrinsically fluorescent probes for metabolic states, cancer detection, and tissue oxygen supply, allowing label-free in vivo imaging of tissues (17, 90a, 124, $125,130)$. NAD(P)/NAD(P)H auto-fluorescence can, therefore, be detected and related to other different physical quantities to gain further details on insight into the processes regulating redox homeostasis. For example, the mechanism by which noise-induced ROS mediates an impairment in acoustic recovery capacity was elucidated by relating intracellular distribution of $\mathrm{NAD}(\mathrm{P}) \mathrm{H}$ in a noise-stressed mammalian cochlea to the generation of lipid peroxides and to the spatial organization of lipids inside membranes. This allowed a disclosure of the mechanism of noise-induced ROS production and impairment in the acoustic recovery capacity (Fig. 2) (96). Skala et al. (127) combined cellular redox ratio, $\mathrm{NAD}(\mathrm{P}) \mathrm{H}$ and FAD lifetime, and subcellular morphology to quantitatively detect $\mathrm{NAD}(\mathrm{P}) \mathrm{H}$. With this approach, metabolic and structural modifications at the earliest stages of cancer development have

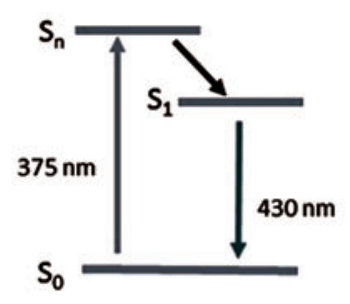

Single photon excitation
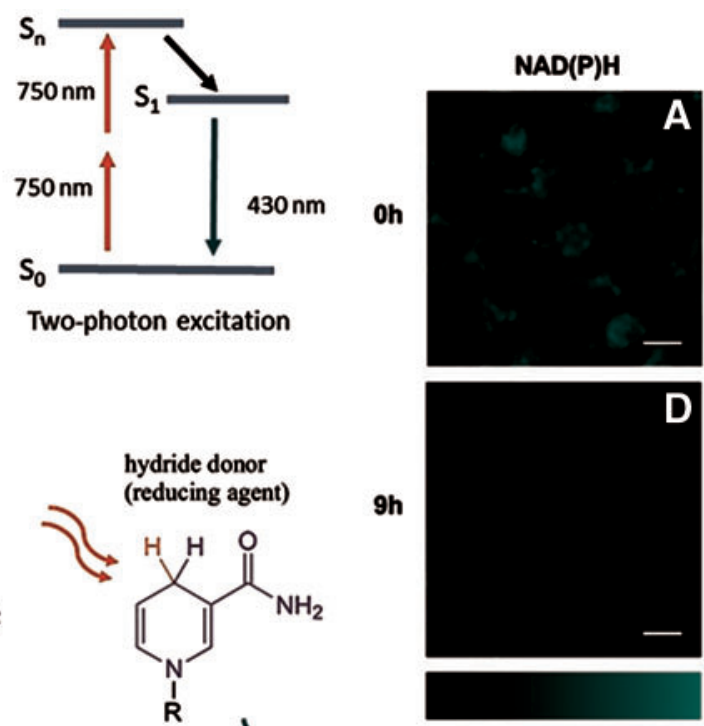
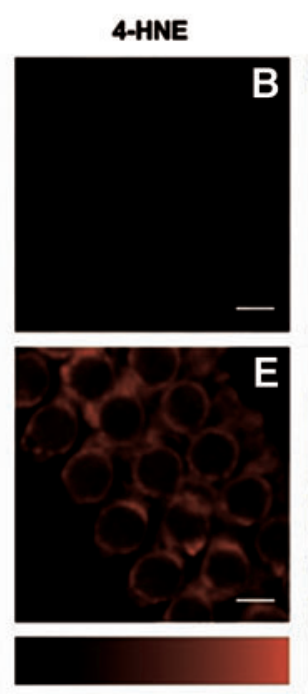
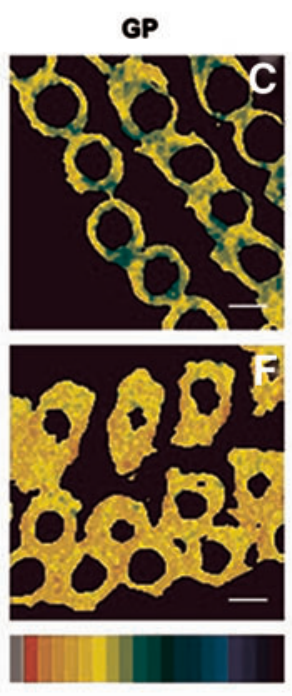

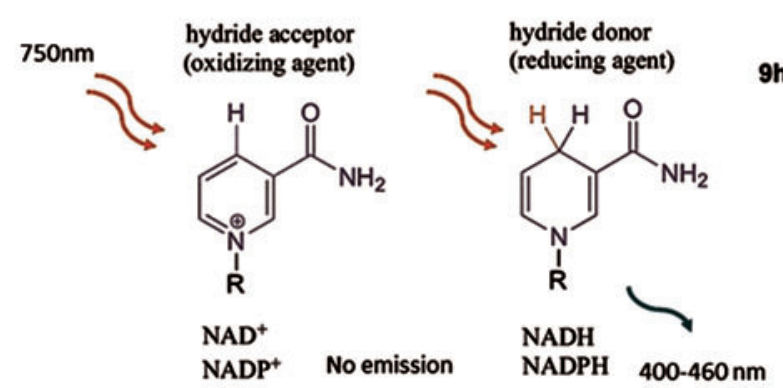

FIG. 2. Acoustic trauma induces $\mathrm{NAD}(\mathrm{P}) \mathrm{H}$ oxidation, lipid peroxidation, and loss of membrane fluidity. $\mathrm{NAD}(\mathrm{P}) \mathrm{H}$ can be excited by a one-photon process: For example, it can absorb one photon at $375 \mathrm{~nm}$, and emit one photon at $430 \mathrm{~nm}$. In the two-photon process, NAD $(\mathrm{P}) \mathrm{H}$ absorbs two photons of $750 \mathrm{~nm}$ whose individual energy is about one half of the energy needed to excite that molecule. $\mathrm{NAD}(\mathrm{P}) \mathrm{H}$ does not emit fluorescence in its oxidized state. (A) Representative fluorescence $\mathrm{NAD}(\mathrm{P}) \mathrm{H}$ images at different time points $(n=5$ animals per time point) after the trauma. (B) $4-\mathrm{HNE}$ assays at different times after acoustic trauma. (C) Fluidity maps at different times after acoustic trauma. (D) Reduced NAD(P)H percentages at different times after the trauma. From the figure, the topologically differentiated NAD(P)H oxidation is also evident on the outer, middle, and inner rows of OHCs. (E) 4-HNE concentrations at different times after acoustic trauma. (F) GP values of hair bundle region (maximum of the GP profiles) at different times after the trauma. Adapted from Maulucci et al. (96). Reprinted with permission of Elsevier. NADPH, nicotinamide adenine dinucleotide phosphate. To see this illustration in color, the reader is referred to the web version of this article at www.liebertpub.com/ars 
been identified in several epithelial tissues in vivo. Moreover, cell Phasor, a label-free, fit-free, and sensitive innovative method that allows classification of metabolic states of cells during differentiation, has been developed from TP-FLIM data (129). Zhuo et al. (17) used two-photon autofluorescence and second harmonic generation (SHG) microscopy to monitor cancer progression and to classify normal and dysplastic human colonic tissues. Overall, these findings demonstrate that autofluorescence can provide structural and functional information for the diagnosis and therapy of pathologic epithelial tissues.

\section{Two-photon $\mathrm{H}_{2} \mathrm{O}_{2}$-sensitive probes}

Hydrogen peroxide plays a key role as a cellular second messenger in a variety of signal transduction processes (30). Genetically encoded fluorescent proteins HyPer, HyPer-3, and roGFP2-Orp1 enabled transient live-cell imaging and allowed high-resolution $\mathrm{H}_{2} \mathrm{O}_{2}$ imaging with high specificity (41). However, these probes are applicable only to singlephoton FRIM or FLIM and have limited application in vivo, since they may alter redox homeostasis and are genetically encoded. Several TP probes have been generated to monitor the production of intracellular $\mathrm{H}_{2} \mathrm{O}_{2}(41)$, but their potential TP-FRIM applications have yet to be tested. For the TPFRIM imaging approach, a promising probe is Peroxy Naphthalene 1 (PN1). This probe can be excited at $750 \mathrm{~nm}$, and it has high photostability and negligible toxicity. It also allows the determination of $\mathrm{H}_{2} \mathrm{O}_{2}$ distribution in live cells and tissue by TPM (19).

\section{Two-photon NO-sensitive probes}

Many of the NO-sensitive probes are not reversible sensors, as they form covalent bonds with $\mathrm{NO}^{\bullet}$. Genetically encoded FRET-based proteins allow high-resolution NO imaging in cell-based experiments (122). However, in vivo applications of these probes are very limited. For NO detection in an in vivo context, a TPM probe (QNO) with high selectivity, low cytotoxicity, $\mathrm{pH}$ insensitivity, and longwavelength emission has been designed (27). QNO is composed of a quinoline derivative as the fluorophore and an $o$-phenylenediamine moiety as the receptor for NO, linked with glycinamide. The probe responded to NO over a linear range from 0.4 to $3.4 \mu M$ with a detection limit of $0.084 \mu M$. QNO detects NO in living cells and tissues at a depth of $180 \mu \mathrm{m}$. However, TP-FRIM/FLIM properties are still not tested and further improvements in the development of NOspecific redox probes are needed.

\section{Chemiluminescent Imaging of ROS In Vivo}

\section{NIR fluorescence and chemiluminescence}

Over the previous decade, substantial progress has been made in the noninvasive real-time assessment of reactive oxygen and nitrogen species in biological systems. Bioimaging methods based on fluorescence and reaction-based approaches have received most attention, due to their ease of use, sensitivity, and selectivity to different reactive species, including reactive oxygen, nitrogen, and sulfur species. A key interest in this rapidly growing field has been the development of chemoselective probes, that is, probes that are diagnostic for a single reactive species. A great number of different reaction schemes have been exploited toward achieving this goal [reviewed in Chan et al. (16)], as summarized in Table 1. Moreover, the reaction-based monitoring of selective species can be combined with targeting of the probe to specific cellular organelles, as exemplified by the boronate MitoPY 1 for the imaging of mitochondrial $\mathrm{H}_{2} \mathrm{O}_{2}$ (24).

Although fluorophores have been used widely for cellular imaging of reactive species, they have a number of limitations that restricts their successful application to tissues and animals. For the latter, fluorophores with absorption and emission maxima in the near-infrared region $(650-900 \mathrm{~nm})$ are required to maximize tissue penetration and, at the same time, to minimize interference from auto-fluorescence and hemoglobin absorption. Nagano and co-workers recently synthesized the near-infrared fluorescent probe FOSCY-1 to monitor reactive species in a mouse model of peritonitis (105). As this probe reacts with several biologically relevant reactive species, it provides general information about the presence of oxidative events rather than about the participation of specific reactive species in vivo. In a further development, the same group designed and synthesized novel far-red to near-infrared probes based on Si-rhodamine to selectively and noninvasively monitor $\mathrm{HOCl}$ in real time in mice suffering from peritonitis (70). Judged by the advances over the previous decade, it can be reasonably expected that the development of additional reactive species-specific and -nonspecific far-red to near-infrared fluorescent probes will progress rapidly.

Reaction-based methods to detect reactive species are also applicable to in vivo imaging modalities other than fluorescence. Chemiluminescence, for example, was used to monitor oxidative events in vivo. Perhaps the most commonly used probe is L-012, an analog of luminol (5-amino-2,3-dihydro-1, 4-phthalazinedione) that produces much stronger signals than

Table 1. Diagnostic Probes for a Single Reactive Species

\begin{tabular}{|c|c|c|c|c|}
\hline Reactive species & Subclassification & Structure & Biological Half-life(s) & Reference \\
\hline Hydrogen peroxide & ROS & $\mathrm{H}_{2} \mathrm{O}_{2}$ & $10^{-5}$ & $(38)$ \\
\hline Hydroxyl radical & ROS & $\mathrm{HO \bullet}$ & $10^{-9}$ & $(20,38)$ \\
\hline Hypochlorous acid & ROS & $\mathrm{HOCl}$ & unknown & unknown \\
\hline Nitric oxide & RNS & $\mathrm{NO}$ & $10^{-3} \div 1$ & $(63,106,112,70 a)$ \\
\hline $\begin{array}{l}\text { Peroxyl radical, including } \\
\text { alkylperoxyl and hydroperoxyl } \\
\text { radicals (wherein } \mathrm{R}=\mathrm{H} \text { ) }\end{array}$ & ROS & ROO• & $10^{-1} \div 1$ & (20) \\
\hline Peroxynitrite anion & RNS & $\mathrm{ONOO}^{-}$ & $0^{-2} \div 1$ & $(6,106)$ \\
\hline Superoxide anion & ROS & $\bullet \mathrm{O}_{2}^{-}$ & $0^{-6}$ & $(38,62)$ \\
\hline
\end{tabular}

ROS, reactive oxygen species. 
luminol, lucigenin, or MCLA (59). L-012 has been used successfully to noninvasively image different inflammatory processes in mice [26-28]. The probe reacts with several highly reactive species rather than being specific, for example, for $\mathrm{O}_{2}{ }^{\bullet-}$, even though L-012-derived luminescence was abolished in mice lacking phagocyte NOX activity (66).

Although much emphasis is placed on chemoselective bioimaging, reactive species in biological systems likely exist as mixtures of rapidly interconverting species. As a result, the biological relevance of a single imaged species is difficult to assess, even if its presence correlates with the biological process studied, as exemplified earlier with L-012 in NOX2-deficient mice (66). In this context, nonspecific probes that react with several different reactive species can have the advantage of probably giving more general information on a biological process (e.g., inflammation) than do selective probes. Indeed, when combined with LC/MS/MSbased analytical analysis of the nonreacted probe as well as its different types of reaction products, nonselective probes may be seen as multi-purpose probes that provide quantitative information about different reactive species, as exemplified recently with hydroethidine (88).

\section{Chemiluminescent nanoparticles and ROS imaging}

Nanoparticles (NPs) are particles with at least one dimension less than $100 \mathrm{~nm}$. They have different shapes, unique physicochemical properties, and a high surface-areato-volume ratio. NPs have several advantages over smallmolecule probes used in cellular sensing and imaging (142). First, NPs have stronger luminescent emission due to the large number of molecular probes that can be loaded into each particle. Additionally, their high surface-area-tovolume ratio provides a higher probability for analyte detection. The NPs may also protect the sensory contents from external interference, such as undesirable enzymatic reactions and nonspecific uptake by proteins. Moreover, it is also possible to target NPs to cells and subcellular compartments by conjugating appropriate ligand moieties onto their surface, which will allow for enhanced targeting to cells and subcellular compartments. Encapsulation and conjugation of different molecules, such as luminescent probes, proteins, or DNA, provides infinite possibilities in NP design for specific functions. In view of all of the earlier mentioned properties, NPs are becoming widely used tools in the field of sensing and imaging (Fig. 3) (115, 119).

Recent advances in developing various luminescence probes have enabled monitoring of ROS in both cells and animals. NP-based luminescent ROS sensors and their applications are summarized in Table 1. Lee et al. (77) developed peroxalate-based NPs formulated from peroxalate esters and fluorescent dyes to image $\mathrm{H}_{2} \mathrm{O}_{2}$ in vivo with high specificity and sensitivity. Peroxalate NPs are capable of imaging $\mathrm{H}_{2} \mathrm{O}_{2}$ in the peritoneal cavity of mice during a lipopolysaccharide-induced inflammatory response. The same group has improved the method by reducing the size of the NPs and modifying their content to detect $\mathrm{H}_{2} \mathrm{O}_{2}$ at physiological concentrations $(22,78)$. Luminescent NPs have also been exploited for in vivo targeting and imaging of tumor tissues. In a recent study, chemiluminescent NPs were successfully developed to image $\mathrm{H}_{2} \mathrm{O}_{2}$ as a tumor signal molecule (18). Such probes improve the stability of peroxalates in aqueous systems and are sensitive to low, physiologically relevant concentrations of $\mathrm{H}_{2} \mathrm{O}_{2}$ within the physiological range. This way of monitoring $\mathrm{H}_{2} \mathrm{O}_{2}$ should be helpful for a clinical diagnosis of other ROS-related diseases.

\section{Ultrasound in ROS Imaging}

Ultrasonic imaging has been applied in many studies to detect changes in functional blood flow and atherosclerotic plaque associated with oxidative stress (84). Although radical oxidants cannot currently be directly detected in a clinical setting with ultrasound, a variety of original methods are being developed to enable such detection. Proposed approaches vary widely, but all rely on the central principle behind clinical contrast ultrasonography - the high sensitivity of ultrasound to echoes from gas bodies.

Contrast-enhanced ultrasound detects strong acoustic echoes when the ultrasonic pulse encounters micrometric gas-bubble contrast agents. A very specific acoustic signature can be obtained from microbubbles when they are acoustically driven at levels resulting in a nonlinear response during the compression and expansion phases of the microbubble. Several, very different solutions for detection of radical oxidants have been proposed based on the
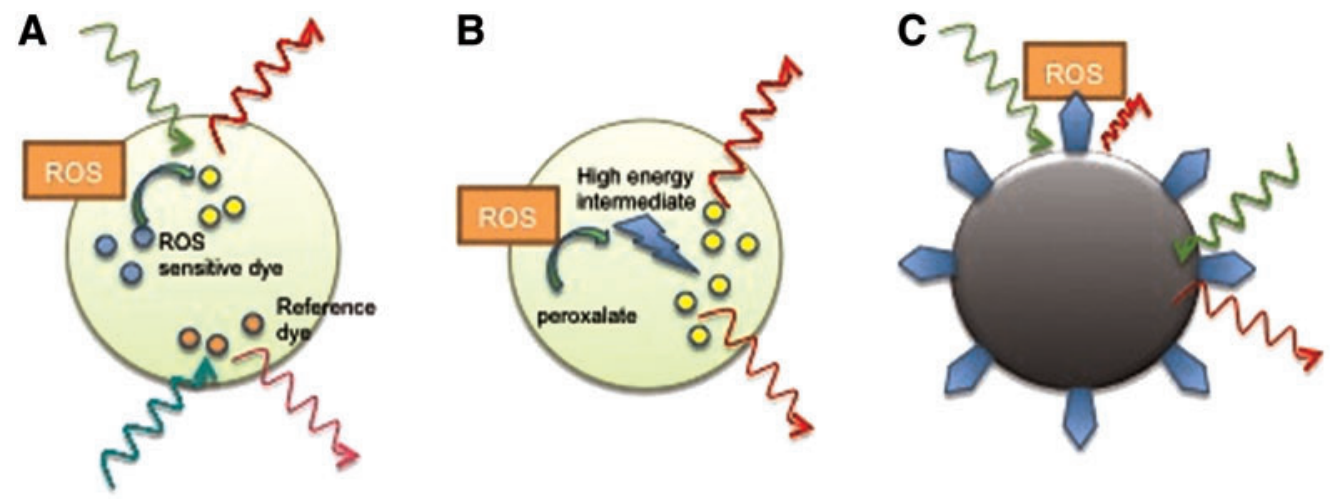

FIG. 3. Examples of NPs adapted for ROS sensing. (A) Polymer-based NPs embedded with ROS sensing and reference fluorescent dyes; (B) Chemiluminescent NPs; (C) Metallic NP fluorescence quenching on oxidation of functionalized ROSsensitive molecules (blue). Adapted from Uusitalo and Hempel (142). Reprinted with permission of MDPI. NP, nanoparticles. To see this illustration in color, the reader is referred to the web version of this article at www.liebertpub.com/ars 
ultrasonic detection of microbubbles that are targeted to specific ligands, which are generated by chemical reactions or produced by micromotors.

Feasibility to detect inhibition of NOX in advanced atherosclerosis has been shown in mice using targeted contrast microbubbles bearing ligands for endothelial cell adhesion molecules that are involved in monocyte recruitment (84). Lipid-shelled decafluorobutane microbubbles were targeted to P-selectin or VCAM-1 and detected with a clinical ultrasound system $(7 \mathrm{MHz}), 8 \mathrm{~min}$ after injection at regions of atherosclerotic plaque in the aortic arch of mice. Inhibition of NOX was associated with decreased targeted detection of Pselectin and VCAM-1. This targeted ligand approach is the basis for a large amount of research in ultrasonic molecular imaging, but it remains to be a relatively indirect approach to assess oxidative stress. A more direct, bio-sensing ultrasound contrast agent for ROS detection has been proposed based on chemical reactions that generate gas-forming molecules in the presence of radical oxidants (108). In the presence of radical oxidants, allylhydrazine oxidizes into 2-propenyldiazene that spontaneously undergoes a retro-ene reaction to generate gas-forming nitrogen and propene molecules. Allylhydrazine encapsulated in phospholipid liposomes (APLs) were produced (60 to $110 \mathrm{~nm}$ in diameter) and injected intravenously in mice. Images of the liver obtained $10 \mathrm{~min}$ after APL injection with a $14 \mathrm{MHz}$ Siemens Acuson Sequoia 512 clinical ultrasound system were shown to present $40 \%$ higher video intensity in mice with inflammation as compared with mice without inflammation. APLs were specific to the hydroxyl radical, and it was further demonstrated that ultrasonic detection of APLs is sensitive to radical oxidant concentrations as low as $10 \mu M$. Even more recently, micromotor converters (MMCs) have been designed to produce microbubbles when $\mathrm{H}_{2} \mathrm{O}_{2}$ is present (104). Tubular MMCs with a platinum-coated inner surface were constructed to break down $\mathrm{H}_{2} \mathrm{O}_{2}$ as fuel while expelling an oxygen-microbubble trail. When injected in an in vivo model for abscess in rats, contrast-specific imaging revealed increased image brightness.

\section{PET/SPECT In Vivo Imaging of Oxidative Stress Using Radiotracers}

The nuclear medicine imaging techniques PET and SPECT are based on noninvasive detection of the distribution of radioactively labeled molecules (radiotracers), and they combine an exquisite sensitivity (down to the femtomolar range) with a relatively low spatial resolution (one to a few millimeters). After it has been injected intravenously, the radiotracer circulates in body fluids, interacts with molecules such as membrane receptors, transporters, enzymes, structural proteins, etc., and/or is transformed by local tissue conditions, for example, blood flow, $\mathrm{pH}$, redox potential, etc. Over time, the distribution of the radiotracer is modified according to the molecular composition of different parts of the body, creating the contrast in PET and SPECT images. With an ideal, that is, diffusible/high-affinity/low nonspecificity radiotracer, the laws of molecular interactions that govern reversible binding or irreversible trapping apply and allow derivation of truly quantitative information from the images, such as the concentration of a target protein or the activity of a target enzyme. Unfortunately, any PET or SPECT radiotracer that binds directly to ROS species has not been described so far. However, radiotracers that can image events correlating more or less with oxidative stress are available, that is, in increasing relevance order: (i) glucose consumption, (ii) cellular retention depending on the cytoplasmic redox potential, and (iii) radiotracers targeting ROS scavengers and the mitochondrial complex I-IV.

\section{Imaging glucose consumption as a surrogate of oxidative stress}

The radiotracer that is most widely in use is $\left[{ }^{18} \mathrm{~F}\right]$ Fluorodeoxyglucose (FDG), a glucose analog transported into the cells principally by GLUT-1 and GLUT-3. FDG is trapped in the cell cytoplasm after its phosphorylation by hexokinase to FDG-6-phosphate. The rate of radioactivity accumulation reflects local glucose consumption, and PET imaging with FDG is used universally for imaging glucose-avid tissues such as the brain or tumors. Jung et al. reported an indirect link between FDG uptake and ROS concentrations in cancer cell lines and tumor-bearing mice (61). They observed a parallel reduction of 30-50\% of FDG uptake and ROS concentration after administration of resveratrol at doses of 50$150 \mu M$ in vitro and $100 \mathrm{mg} \mathrm{kg}^{-1}$ in vivo. The ROS scavenger $\mathrm{N}$-acetylcysteine had the same effect, whereas ROS inducers had an opposite effect (20-40\% increase) on FDG uptake in vitro. Resveratrol treatment decreased the expression of the membrane glucose transporter GLUT-1.

The report by Jung et al. suggesting a relationship between FDG uptake and oxidative stress remains to be confirmed by other studies. In fact, a number of separate studies tend to indicate that increased oxidative stress is associated with glucose hypometabolism in neurodegenerative disorders, (99). Thus, it is likely that FDG uptake and ROS production are indirectly linked to other co-occurring factors. Further studies are necessary to determine whether the possibility to image changes in ROS production using PET imaging is relevant to specific diseases and/or to particular pharmacological challenges.

\section{Radiotracers with redox potential-dependent cellular retention}

Popular SPECT radiotracers for imaging tissue perfusion [76], such as [ $\left.{ }^{99 \mathrm{~m}} \mathrm{Tc}\right]-\mathrm{HMPAO},\left[{ }^{99 \mathrm{~m}} \mathrm{Tc}\right]-\mathrm{HL}-91$, and [ $\left.{ }^{99 \mathrm{~m}} \mathrm{Tc}\right]-$ MIBI, are redox couples that, depending on the redox potential of the medium, can switch from a reduced, lipophilic, membranepermeable form to an oxidized, hydrophilic, nonmembranepermeable form. These radiotracers have high octanol-water coefficients and cross cell membranes freely in a few seconds. Once in the intracellular space, they are oxidized in the cytosol by glutathione or reduced proteins and the radioactive signal builds up through trapping of the membrane-impermeable oxidized form, leading to radioactivity concentrations that are proportional to perfusion in the normally perfused brain or myocardium for [ $\left.{ }^{99 \mathrm{~m}} \mathrm{Tc}\right]-\mathrm{HMPAO}$ and $\left[{ }^{99 \mathrm{~m}} \mathrm{Tc}\right]-\mathrm{MIBI}$, respectively [43-44]. Conversely, defects in tissue perfusion after stroke or myocardial ischemia appear as a negative contrast on scintigraphic or SPECT images. Interestingly, the trapping of these radiotracers is also impaired after oxidative stress, suggesting that $\left[{ }^{99 \mathrm{~m}} \mathrm{Tc}\right]-\mathrm{HMPAO}$ and $\left[{ }^{99 \mathrm{~m}} \mathrm{Tc}\right]-\mathrm{MIBI}$ can negatively image changes in the cellular redox state, although it is not clear whether the cause is a drop in glutathione concentration or a modification of the redox status (101). 
Sasaki et al. examined the redox potential in the brains of young and old male $\mathrm{DBF}_{1}$ mice using $\left[{ }^{99 \mathrm{~m}} \mathrm{Tc}\right]-\mathrm{HMPAO}$, glucose transport, and metabolism using $\left[1-{ }^{14} \mathrm{C}\right] 2$-deoxy-Dglucose (2-DG), and mitochondrial electron transport function using $\left[{ }^{15} \mathrm{O}_{2} \mathrm{O}_{2}(121)\right.$. They found a decrease of $\left[{ }^{99 \mathrm{~m}} \mathrm{Tc}\right]-$ HMPAO brain uptake at 24 and 30 months of age, a late decrease of $\left[{ }^{15} \mathrm{O}\right] \mathrm{O}_{2}$ uptake at 30 months, and a trend toward increased 2-DG uptake with aging. Blankenberg and colleagues (13) used [ $\left.{ }^{99 \mathrm{~m}} \mathrm{Tc}\right]-\mathrm{HMPAO}$ to evaluate the efficacy of a novel redox-modulating agent in patients with rare and fatal mitochondrial brain diseases, including Leigh syndrome, polymerase $\gamma$ deficiency, MELAS, Friedreich ataxia, KearnsSayre syndrome, Pearson syndrome, and mtDNA depletion syndrome. Although no control group could be included for obvious ethical reasons and the number of patients was limited, they observed a significant correlation between clinical improvement after treatment and reduced ${ }^{99 \mathrm{~m}} \mathrm{Tc}-\mathrm{HMPAO}$ brain uptake, suggesting that $\left[{ }^{99 \mathrm{~m}} \mathrm{Tc}\right]-\mathrm{HMPAO}$ may be a useful marker of redox state in brain regions under conditions of chronic oxidative stress.

\section{Radiotracers with hypoxia-dependent cellular retention}

Radiotracer imaging of hypoxia is based on the principle of free diffusion according to plasma flow followed by specific trapping of the radiotracer in hypoxic tissues. Several radiotracers are based on nitroimidazole derivatives such as the fluorine-18-labeled fluoromisonidazole ( $\left.\left[{ }^{18} \mathrm{~F}\right] \mathrm{FMISO}\right)$. Once inside the cell, the nitro group of $\left[{ }^{18} \mathrm{~F}\right] \mathrm{FMISO}$ is reduced to a nitro radical anion that is immediately reoxidized by oxygen in normoxic conditions. Conversely, under low oxygen pressure, $\left[{ }^{18} \mathrm{~F}\right] \mathrm{FMISO}$ is not re-oxidized but undergoes further reduction by electron transfer, leading to reactive species that form adducts with proteins and nucleic acids. Since radioactivity is trapped in hypoxic conditions, $\left[{ }^{18} \mathrm{~F}\right] \mathrm{FMISO}$ administration produces positive images of tissue hypoxia, that is, the lower the oxygen pressure, the higher the radioactivity concentration. However, the relationship between uptake and hypoxia is not straightforward in all tissues because of the complex metabolism of $\left[{ }^{18} \mathrm{~F}\right] \mathrm{FMISO}$ and because of its slow clearance from normoxic tissue (102), whereas ${ }^{18} \mathrm{~F}$ has a half-life of less than $2 \mathrm{~h}$. In attempts to obtain more suitable radiotracers, other nitroimidazole derivatives such as $\left[{ }^{18} \mathrm{~F}\right]-,\left[{ }^{124} \mathrm{I}\right]$-, and $\left[{ }^{123} \mathrm{I}\right]$-azomycin derivatives (IAZA, IAZGP, FAZA, respectively) (103) have been developed for PET and SPECT imaging, as well as non nitroimidazole compounds, including $\left[{ }^{62} \mathrm{Cu}\right]-$ and $\left[{ }^{64} \mathrm{Cu}\right]-$ PTSM, [ $\left.{ }^{99 \mathrm{~m}} \mathrm{Tc}\right]-A T S M,\left[{ }^{99 \mathrm{~m}} \mathrm{Tc}\right]-\mathrm{HL}-91$, etc , have been developed. (5). Several of these compounds are commercially available and are in clinical use for the staging of tumors according to their hypoxic status and/or to assess radiotherapy- or chemotherapy-induced hypoxia. Consensus on the utilization of hypoxia tracers and on the correlation between their capacity to image hypoxia and ROS production remains to be defined.

\section{Radiotracers targeting ROS scavengers or mitochondrial complex I-IV}

An "old" radiotracer that recently regained interest is [ $[99 \mathrm{~m}$ Tc]-DTPA-glutathione ([ $\left.\left.{ }^{99 \mathrm{~m}} \mathrm{Tc}\right]-\mathrm{GSH}\right)$, a labeled derivative of the intracellular tripeptide glutathione that is present in all tissues where its physiological function is to neutralize ROS
(31). The transporter of GSH is overexpressed in cancer cells, leading to higher concentrations of GSH in tumors, in particular during multidrug and radiation resistance and in metastatic cancers. It was recently reported that the uptake of [ ${ }^{99 m}$ Tc]-GSH is high in CT-26 colon cancer xenografted in mice with tumor-to-muscle ratios reaching 4.3 at $4 \mathrm{~h}$, compared with 2.0 in inflammatory tissue with lower ROS levels (67).

There have been continuous efforts by Japanese groups to develop radiotracers directly targeting the mitochondrial complex I-IV (MC I-IV) of the respiratory electron transport chain. Sasaki et al. have reported the labeling of $\left[{ }^{11} \mathrm{C}\right]$ idebenone, a coenzyme Q (CoQ)-related compound, and compared its biodistribution with that of $\left[{ }^{11} \mathrm{C}\right] \mathrm{CoQ}_{0}(120)$. Although $\left[{ }^{11} \mathrm{C}\right] \mathrm{CoQ}_{0}$ was better retained in cerebral tissue than $\left[{ }^{11} \mathrm{C}\right]$ idebenone, its clearance from the blood circulation was too slow for in vivo imaging of the brain given the halflife of carbon-11 (20.4 min). The authors concluded that further modifications of the isoprenoid side chain in $\left[{ }^{11} \mathrm{C}\right] \mathrm{CoQ}$ would be necessary to obtain more suitable radiopharmaceuticals. Recently, Tsukada et al. developed fluorine-18 derivatives of BMS-747158-01, an inhibitor of the PSST subunit of MC I, among which $\left[{ }^{18} \mathrm{~F}\right] \mathrm{F}-\mathrm{BCPP}-\mathrm{EF}$ showed interesting pharmacokinetics in rats and monkeys, with rapid uptake into the brain and heart followed by gradual elimination (138). Specificity of the uptake was demonstrated using predosing with rotenone as a specific MC-I inhibitor. $\left[{ }^{18} \mathrm{~F}\right] \mathrm{F}-\mathrm{BCPP}-\mathrm{EF}$ was used to image the extent of neuronal damage in a rat model of brain ischemia, and the ageassociated neuronal impairment of MC I activity in the brain of living monkeys (Fig. 4).

\section{Magnetic Resonance Modalities}

\section{Basic principles and technical considerations}

Electron paramagnetic resonance, EPR (or equivalently, electron spin resonance) is a spectroscopic technique that can directly detect paramagnetic species (species having an electronic spin due to the unpaired electron). However, there is very little to be observed by EPR in biological systems apart from some stable carbon-centered radicals, melanin, or transition metals. ROS such as superoxide or the hydroxyl radical are much too short lived to be detected by conventional EPR. Therefore, EPR detection of ROS can be accomplished by techniques that are not always direct. The scheme in Figure 5 explains the basic principles and strategies in ROS imaging. Injection of an EPR-visible nitroxide allows its detection in various organs in vivo. Endogenous ROS react with nitroxide, reducing it to an EPR-silent hydroxylamine and thus diminishing the EPR signal. The rate of reduction is the measure of the redox status of the tissue. But one has to be careful when interpreting such data, since the signal decay rate depends on several kinetic factors such as the distribution of the spin probe from the blood to the tissue and vice versa, urinary excretion through kidneys, and fecal excretion through liver and bile. Nevertheless, EPR monitoring of the decay rate of the injected nitroxide is the most efficient way to assess the redox metabolism in vivo, since one can use various nitroxides to unravel different processes. The alternative to this approach is to use acyl-protected hydroxylamine, which, introduced in the tissue, can be easily deprotected inside cells by intracellular esterases and then converted to the EPR-visible species by ROS-induced 


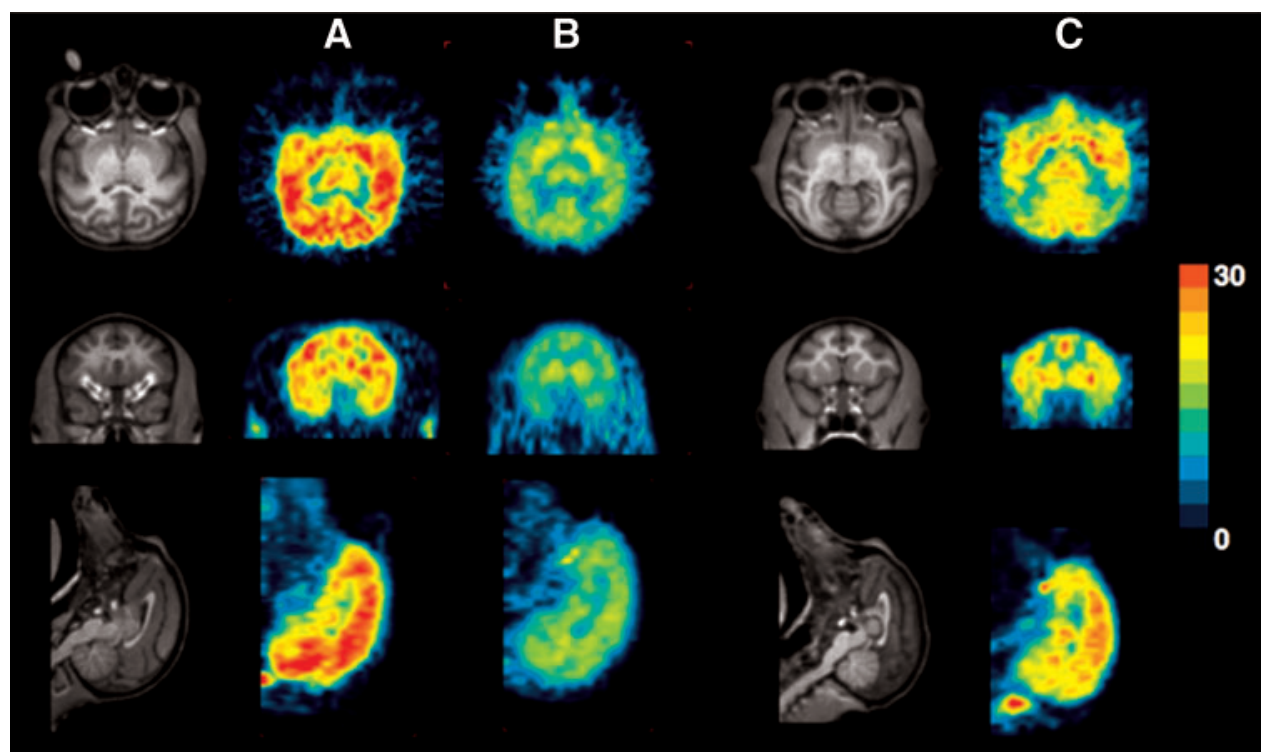

FIG. 4. Age associated neuronal impairment of MC I activity in the brain of living monkeys. Typical MR and PET images of ${ }^{18} \mathrm{~F}$-BCPP-EF in (A) normal young, (B) rotenone-treated young, and (C) normal old monkeys (Macaca mulatta). After infusion of vehicle $(\mathbf{A}, \mathbf{C})$ or rotenone at $0.1 \mathrm{mg} / \mathrm{kg} / \mathrm{h}(\mathbf{B})$ for $1 \mathrm{~h}$, PET scans were acquired for $91 \mathrm{~min}$ after ${ }^{18} \mathrm{~F} \cdot \mathrm{BCPP}-$ EF injection with sequential arterial blood sampling. The binding of ${ }^{18}$ F-BCPP-BF to MC-1 was calculated using Logan graphical analysis with rnetabolite-corrected plasma input. Adapted from Tsukada et al. (139). Reprinted with permission of Springer. MRI, magnetic resonance imaging; PET, positron emission tomography. To see this illustration in color, the reader is referred to the web version of this article at www.liebertpub.com/ars

oxidation [58]. An entirely different approach to ROS imaging is EPR spin trapping, which is the "true" ROS imaging. The method relies on introducing a compound that will trap short-lived radicals and convert them into more stable paramagnetic compounds (Fig. 5).

Unfortunately, trapped radicals usually have rather complex EPR spectra that are not suitable for imaging. However, since multiple EPR lines do not affect overall paramagnetic properties of the compound, MRI has been successfully used in immuno-spin trapping (136).

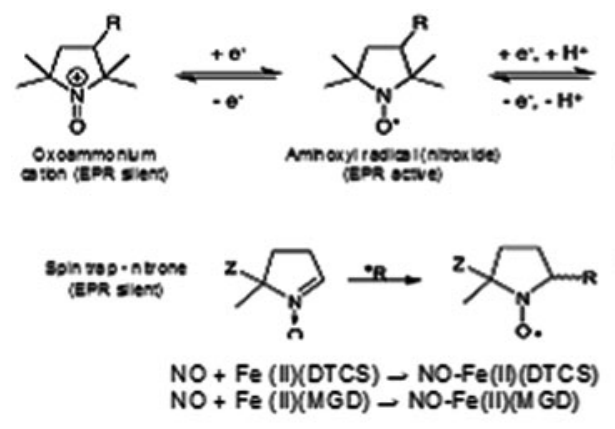

Most of the basic principles of in vivo EPRI/EPRS were established in the 1980s $(4,7,9,26,29,60,100,111,133)$. Much of this work has been stimulated by the discovery that nitroxides can report on the redox metabolism in cells and tissues and that the rate of reduction is highly dependent on the concentration of oxygen [see e.g., (131)]. Since then, several research groups have been developing specific spin probes with an adequate in vivo lifetime and other desirable properties, as well as instruments that are suitable for in vivo EPR. A standard commercial EPR spectrometer operating at $9.5 \mathrm{GHz}$ (X-band)

FIG. 5. Redox reactions associated with EPR-visible species (spectra on the right). Top row. Nitroxides are stable in solutions, but not in biological systems, and can be sensors of redox status due to illustrated reactions. The basic structure can be the pyrrolidine or piperidine ring, which determines relative resistance to reduction (5-membered rings are generally more resistant). These two pairs: hydroxylamine/nitroxide and nitroxide/oxoamonium cation actually mimic cycling antioxidant and superoxide dismutase pairs. The group on the position 3 determines the behavior of the probe (solubility, lipophilicity, membrane penetration, in vivo clearance rate, etc.) and can be tailored to the needs. Middle row. Spin trapping. ROS are trapped with the nitrone trap converting them into a more stable form. Spectrum shows the ability of a trap DEPMPO (5-dietoxyphosphoryl-5-methyl-1-N-oxyde) to capture both superoxide and hydroxyl radicals that can be distinguished by characteristic spectral lines. Bottom row. Trapping of NO using DETC (diethyldithiocarbamate) or MGD ( $N$ Methyl-D-glucamine dithiocarbamate) with different lipid solublility and membrane permeability. Adapted from Berliner and Fujii (7). Reprinted with permission of AAAS. EPR, electron paramagnetic resonance. 
can at best accommodate a mouse tail due to nonresonant absorption of the electromagnetic radiation by the dielectric liquids in biological systems. Imaging of small animals, thus, has been performed at L-band $(1.2 \mathrm{GHz})$ or even lower frequencies (around 700 or $300 \mathrm{MHz}$ ) (10). Commercial EPRI machines suitable for in vivo applications were not available until recently; hence, most researchers used and still are using homemade apparatus or a modification of commercial ones.

The realization that one can introduce metabolically responsive and relatively stable paramagnetic free radicals in the body and detect these processes promptly stimulated the introduction of MR in the area. MRI detects paramagnetic species indirectly, since they increase the relaxation rate of water molecules that can be seen by the enhanced signal on T1weighted images. At the beginning, nitroxides were studied as potential clinical contrast agents, primarily for tumors, but recently they are more often used to study the redox state (14). MRI has no problems in imaging subjects of any size, including humans, since it operates in the frequencies of a few hundreds of $\mathrm{MHz}$, but detection of ROS is indirect.

Both techniques have their advantages and drawbacks in in vivo ROS detection/imaging but the sensible simultaneous use of both is a way to employ the potential of these techniques, which has been demonstrated even for solutions (8). Namely, EPRI does not provide images of anatomy, it just shows the distribution of injected nitroxide within the body, and it does not have good spatial resolution. Conversely, MRI has excellent spatial resolution, but it gives little or no information on the paramagnetic species involved. Hence, using MR as an imaging modality and EPRS in combination can provide unique information $(35,37)$. It is also possible to use both techniques as imaging modalities and overlay EPRI, providing redox information apart from MRI providing anatomic information $(15,44,57)$.

Numerous examples of combining these two techniques in oxymetry imaging can be found elsewhere $(2,81,82,83)$. There are also constructions of dual EPR/MR imaging machines $(32,39,116)$. Probably the best way to fuse EPR and MRI into a single machine is to use the dynamic nuclear polarization (DNP or Overhauser effect) that uses a unique method for radical detection. An entirely different approach has been the combination of X-ray CT with EPRI in studying a mouse knee (11).

Perhaps the most powerful application of in vivo EPRI is measurement of oxygen (EPR oxymetry). This subject will not be covered per se due to limited space, although it is closely connected with the scope of this article. In addition, this subject has been extensively and regularly reviewed. What follows are characteristic examples that illustrate applications of magnetic resonance techniques in imaging ROS, particularly emphasizing how fruitful a combination of EPR and MRI can be in achieving optimal analysis of the investigated subject. A more comprehensive list of examples and a literature overview on EPR imaging of the oxidative stress can be found in the recent review (28), and more technical aspects of various EPR and MRI approaches with examples can be found in $(56,90)$.

\section{Examples of EPRI/MRI of ROS/RNS}

Early EPRI images were rather crude (same as first MRI), and it took some 5-6 min to make crude 2D images using filtered back-projection with only eight projections resulting in low spatial resolution. $(3,111)$. It took full $45 \mathrm{~min}$ to obtain a complete 3D data set (60), which certainly limits temporal studies. However, this research stimulated further development, and today's machines are capable of producing 3D EPR images in around 1 min with up to 80 projections, where the actual performance depends on a selected task $(34,55$, 155). Most research using EPRI and MRI was conducted using derivatives of TEMPO and PROXYL. In the beginning, carboxyl-PROXYL (3CxP, or then termed PCA) has been used $(3,4,111)$, but later carbamoyl-PROXYL (3CP) became almost the universal choice for imaging, although different derivatives, such as hydroxylmethyl (HM-P) and others, have been used, especially in brain imaging $(118,151,155)$. The proper selection of these probes with different properties such as in vivo half-life, membrane permeability, lipid solubility, etc. enables clarification of the location of in vivo ROS generation and redox status. As a rule, piperidine nitroxides have an in vivo half-life of a few minutes whereas the half-life of pyrrolidine is typically around 15 min or more. This is why pyrrolidines are generally used to image metabolism whereas piperidines are useful for probe circulation.

\section{Brain imaging (without tumors)}

The brain, due to its complex structure and function, has been a natural target for ROS EPR/MR imaging since the beginning of development of EPRI (60). This research has been accelerated by synthesis of the blood-brain-barrier permeable nitroxides $(117,140)$ and instrumental developments. Yokoyama et al. published a nice series of articles on various conditions induced in experimental animals (149, 150, 152-154). Figure 6 illustrates the basic concept of timeresolved brain EPRI (153). In rats with kainic-acid (KA)induced seizures, the hippocampal half-life of nitroxide (PCAM) after KA-induced seizures was significantly prolonged, indicating impaired reducing ability; whereas the prolongation of the cortical half-life was not significant. These findings were confirmed by using an acyl-protected hydroxylamine that undergoes intracellular oxidation to nitroxides (150), showing that oxidative stress in the hippocampus and striatum in KA-treated animals is enhanced, but not in the cortex. Another set of studies, performed on the effect of various neuroleptics that are known to induce oxidative stress on the brain, revealed diminished ability of various brain areas in treated animals to reduce injected nitroxide $(149,152,154)$. The study on intracerebralreducing ability after acute stress in adult rats showed diminished reducing ability in rats that were subjected to neonatal isolation (154). Studies employing ischemiareperfusion (I/R) injury induced by mid-carotid-artery occlusion using either only MRI (13) or EPRI/MRI combination (52) revealed slower reduction rates in brains that have undergone I/R. Another common way of altering the redox state is to induce septic shock, and it was shown that reduction rates of injected nitroxides are accelerated in brains of septic mice (36). Radiation is a certain way to induce vast changes in redox status, and various nitroxides have been successfully tested as potential radioprotectors (see (23) and references cited therein). In that study, nitroxides were used as both radioprotectors and indicators of redox status, and pharmacokinetics of nitroxides in brain, salivary gland, tongue, and oral muscle have been determined using MRI. 

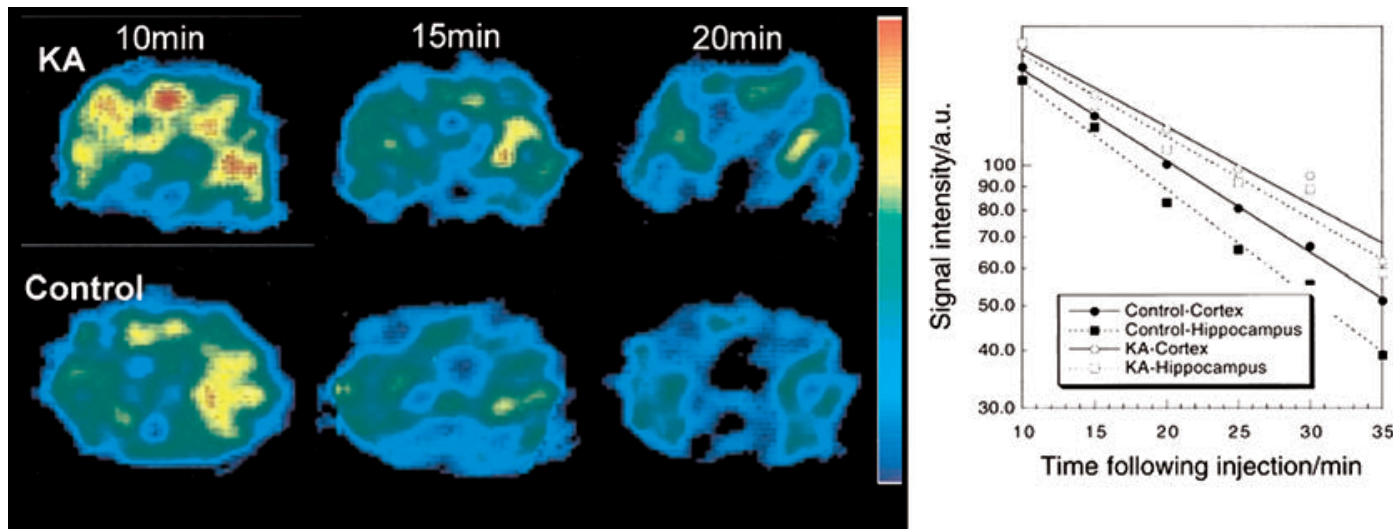

FIG. 6. EPRI of rat brain. Left: The dynamic pattern of selected transversal EPR images of rat head $5 \mathrm{~mm}$ posterior to the bregma in the KA-treated and control groups at different times after injection of PCAM nitroxide. Right: Pharmacokinetic curves for brain regions. The cortical half-lives of PCAM in the control and KA groups were $18.0 \pm 1.2$ and $19.2 \pm 0.7 \mathrm{~min}$, whereas the hippocampal half-lives of PCAM in the control and KA groups were $10.4 \pm 0.8$ and $15.9 \pm 0.7 \mathrm{~min}$, respectively. Adapted from Yokoyama et al. (153). Reprinted with permission of Elsevier. KA, kainic-acid. To see this illustration in color, the reader is referred to the web version of this article at www.liebertpub.com/ars

\section{Tumor imaging}

Due to their heterogeneous structure, tumors have been studied since the introduction of EPRI $(9,26)$. Redox status and oxygenation are important in designing therapy (especially radiotherapy) and/or in assessing tumor response to therapy. Tumors are heterogeneous in both aspects; hence, it is desirable to obtain spatially resolved images of nitroxide distribution and clearance simultaneously within the tumor volume as well as oxygenation, if possible. Various approaches employing the EPR/MRI combination, or individual technique and probe selection, have been used $(37,40,54,58,73,74,98$, $113,132,146,156,157)$. An example of tumor heterogeneity in reduction rates of nitroxide is given in Figure 7. It has been generally concluded that the reduction of nitroxides in tumors is faster than in normal tissue, irrespective of whether the reduction in tumors implanted in the muscle is compared with the muscle $(54,58,73,74,146)$ or when gastric cancer is compared with normal mucosa (98). Faster bioreduction in tumors can be a consequence of an increased amount of endogenous reducing agents such as thiols [reduction was slower in both normal tissue and tumor in animals depleted with thiols (74, 146)], ascorbate, enzymes (Fig. 7). Chemically, nitroxides do not react with thiols, but altering the concentration of the thiol or changing the ratio of redox pairs has an impact on the clearance of the nitroxide; therefore, in vivo reduction of nitroxides also depends on the oxygen content and on the levels of GSH (74). Lack of oxygen, reflecting the well-known fact that reduction is faster in oxygen-depleted tissues, may also be responsible and tumors tend to have large hypoxic regions. Studies of tumors in animals breathing carbogen showed decreased reduction of nitroxides and decreased reduction heterogeneity with increased oxygenation (58), but a simultaneous study on reduction of nitroxides and direct oxymetry showed a rather poor correlation between these in normal air-breathing animals (132).
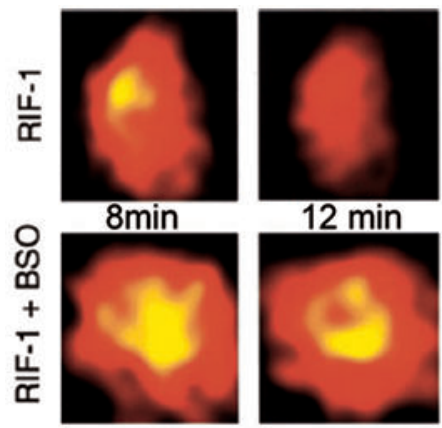
$12 \mathrm{~min}$
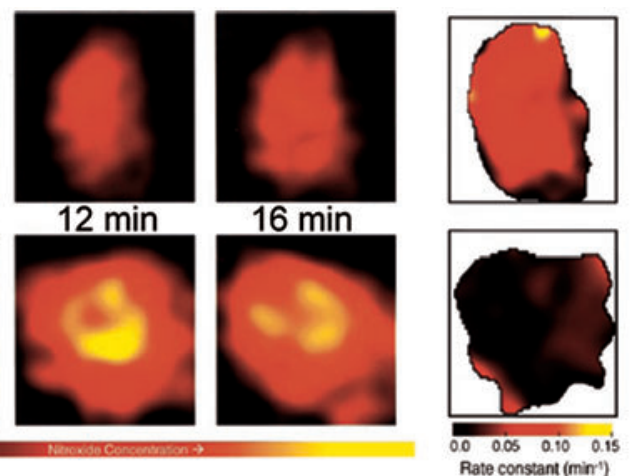

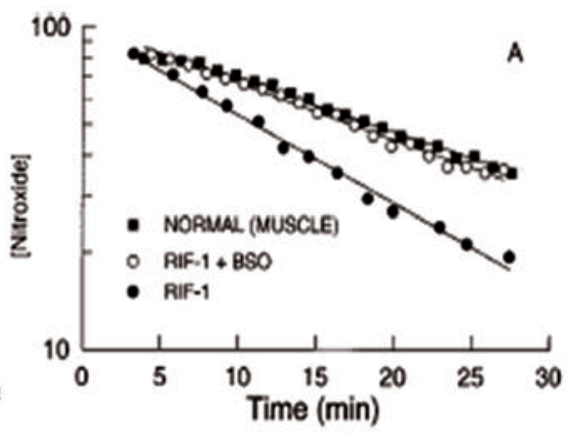

FIG. 7. EPRI of the thigh of mouse with implanted RIF-1 tumor. Left: Selected EPR images of clearance of 3CP nitroxide in untreated and BSO-induced (agent for glutathione synthesis) tumors. Middle: Redox mapping of the tumor. Two dimensional mapping of pseudo-first-order rate constants and frequency plot of 3CP reduction rate constants. Right: The semilog plot showing the whole tissue clearance of nitroxide in tumors and normal muscle of contra lateral leg. Images of tumor and muscle used for the measurement of pharmacokinetic data were collected simultaneously on the same animals. Adapted from Kuppusamy et al.(74). Reprinted with permission of AACR. To see this illustration in color, the reader is referred to the web version of this article at www.liebertpub.com/ars 


\section{Other organs}

Skin is an ideal target organ for EPRI for several reasons. Imaging of ROS does not require a large penetration depth, so one can use the S-band $(2.2-3.0 \mathrm{MHz})$ for in vivo specimens or even X-band for in vitro specimens, which results in improved sensitivity. Imaging does not require full 2D or 3D; once nitroxides are applied topically, a simple spectralspatial 1D imaging with one gradient orthogonal to the skin surface is sufficient to obtain distribution of nitroxides and redox status in different skin layers. Surface loop coils are sufficient, that is, the whole object need not to be within the resonator, which allows EPRI of objects of any size, including humans. The potential of this technique has been nicely demonstrated in an in vivo study of human skin (46), which opens the possibilities of studying various skin pathologies, aging, or photo-damage. The effect of UV exposure on free radical production and redox status of the skin has been studied both in vivo and in vitro (45-47).

Pharmacokinetics of nitroxides in abdominal organs (liver, kidneys, bladder) was first studied by in vivo EPRS (4) and EPRI $(3,111)$. The distribution and reduction/clearance of nitroxides demonstrated the feasibility of EPRI studies. But apart from having low spatiotemporal resolution, it has revealed difficulties in anatomical localization of different organs on EPR images. A decade later, it has been shown that this problem can be overcome by combining EPRI and MRI (44, 57) and that whole-body simultaneous measurements of pharmacokinetics and distribution of nitroxides can be performed on ten different locations within the body (57). These studies were performed to illustrate technical developments, and they were not aimed at investigating any particular pathology. An excellent application of a hybrid EPR/MRI machine has studied the redox status of different organs in mice exposed to cigarette smoke (Fig. 8). On the other hand, different important pathologies were studied using less technically demanding direct time-resolved EPRI. The study of mice liver showed a much slower reduction of 3CP in carbon-tetrachloride damaged liver than in the control (135). Another study of mice with hepatic I/R injury showed that $\mathrm{CV} 159-\mathrm{Ca}^{2+} /$ calmodulin blockade inhibiting $\mathrm{Ca}^{2+}$ overloading has a profound effect on the liver-reducing ability (69). The I/R acute renal failure produced prolonged reduction of 3CP in kidneys (48), whereas it was much faster in the kidneys of diabetic mice (128). The latter study also showed that treatment with angiotensin returns the reduction to the control level, confirming the antioxidant properties of this drug. Another drug (Azelnidipine) has been studied in the murine hypertension model, and it has been found that it improves renal-reducing ability of free radicals, thus ameliorating the renal redox status (49). A somewhat different model of the investigated pathology was employed in a study of reducing activity of kidneys in Nrf 2 transcriptional factor-deficient mice. The combination of deficiency and aging resulted in four times longer half-life of $3 \mathrm{CP}$ in the upper $\mathrm{ab}$ domen than in juvenile wild-type mice, indicating that low reducing ability may play a role in the onset of autoimmune nephritis (50). A set of hydroxylamine spin probes detecting site-specific production of the superoxide radical and allowing subcellular resolution and organelle specificity was developed and used in vivo on several organs. The detection mechanism is based on a rapid reaction of cyclic hydroxylamines with superoxide, producing stable nitroxides (25). These probes were applied in vivo on old rats, showed how ROS generation was significantly increased compared with their young counterparts in blood, skeletal muscle, lung, and heart, but did not change in intestine, brain, liver, and kidney (71).

\section{Imaging of trapped radicals}

This attractive modality offers a possibility to image specific ROS as opposed to previous examples where the overall redox state was imaged. However, EPRI of trapped ROS is

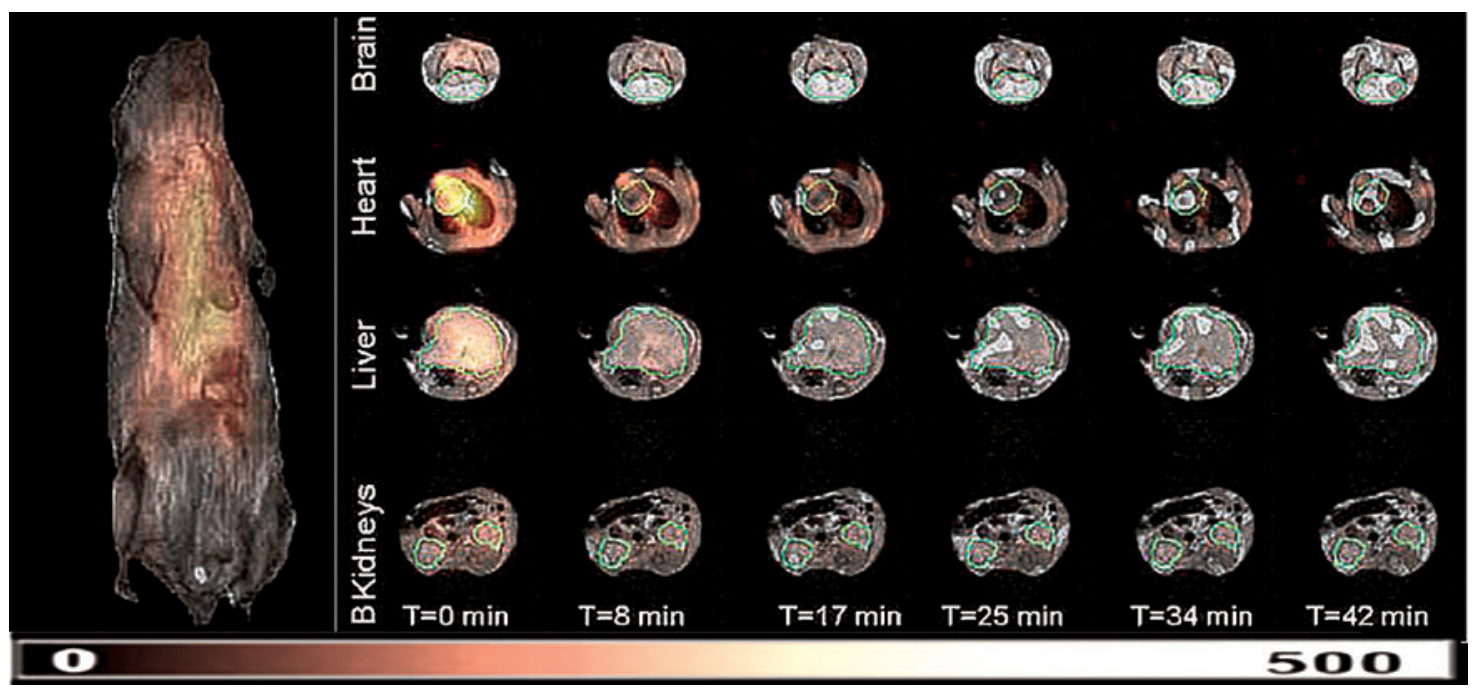

FIG. 8. Renderings of the superimposed 3D EPRI and 3D proton MRI of mice. The color map is for the EPR intensity of the 3CP nitroxide probe distribution. Left: Coronal MR image of mice. Right: Transverse slices through different organs of the animal showing the temporal change of EPR intensity of 3CP. The green contour depicts the ROI used to calculate the average EPR intensity distribution of the probe later used to assess pharmacokinetics. Based on that, it has been found that mice exposed to second-hand smoking have diminished ability to reduce nitroxides in these organs. Adapted from Caia et al. (15). Reprinted with permission of Elsevier. To see this illustration in color, the reader is referred to the web version of this article at www.liebertpub.com/ars 

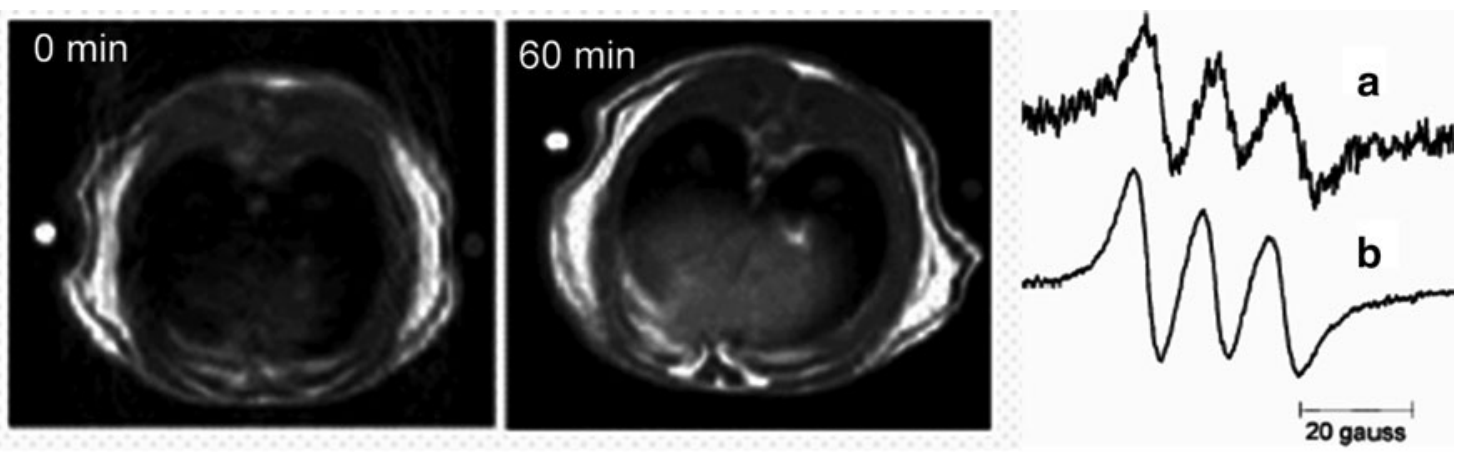

FIG. 9. LPS treated rats. Left: T1W MRI images of the rat abdomen both before and after injection of the NO spin trap. Right: EPR spectra of trapped NO in-vivo on L-band (a) and on excised sample X-band (b), demonstrating that trapped radical is NO and that MRI signal enhancement originates from NO. Adapted from Gallez et al. (37). Reprinted with permission of Wiley.

extremely difficult. First, the concentration of radicals is very low and it requires very high amounts of spin trapping agent to be injected (up to $100 \mathrm{mmol} / \mathrm{kg}$ ), which raises the question of toxicity. Second, EPR spectra of trapped radicals usually contain numerous closely spaced lines of multiple adducts (Fig. 5) and it is almost impossible to isolate specific lines for imaging the selected adduct. Third, trapped products are not very stable, which narrows the time window for imaging. Nevertheless, imaging of trapped NO (Fig. 9) is a good example of how to combine in vivo EPR and MRI. The role of in vivo EPR is not to image radicals but to add the unique information on the nature of the radical species (fingerprinting), which actually enhances the tissue signal on T1W MRI, and a similar approach has been employed in brain imaging (36). Although there are no true images of trapped radicals, useful in vivo studies have been performed for employing specific EPR coils that detect signals only from targeted organs in assessing the usefulness of different traps in detecting radicals (134), NO generation in mice after cardiopulmonary arrest (75), and studies of simultaneous detection of oxygen and NO in the induced septic shock (33). Another example of successful in vivo detection of trapped radical is on the irradiated mouse, since irradiation produces a large amount of free radicals (43). Imaging of spin-trapped superoxide or hydroxyl radical could be improved by developing more resistant spin traps and using ${ }^{15} \mathrm{~N}$-substituted probes, which will improve sensitivity and resolution by decreasing the number of EPR lines [see the nice review on in vivo trapping (64)].

\section{Dynamic nuclear polarization DNP-MRI (OMRI, PEDRI)}

This technique deserves to be treated separately due to the unique detection mechanism and high potential for in vivo measurements, although the aim of these studies is the same as outlined earlier. DNP is not a simple overlaying of separate EPR and MR images obtained in a hybrid apparatus but a technique that includes parts of EPRI and MRI. Detection of radicals (unpaired electron spin) is based on a different principle. There are several DNP mechanisms (89), but most of the biological applications have been performed using the classical Overhauser effect, hence Overhauser MRI or OMRI. The first experiment using nitroxides and transfer to
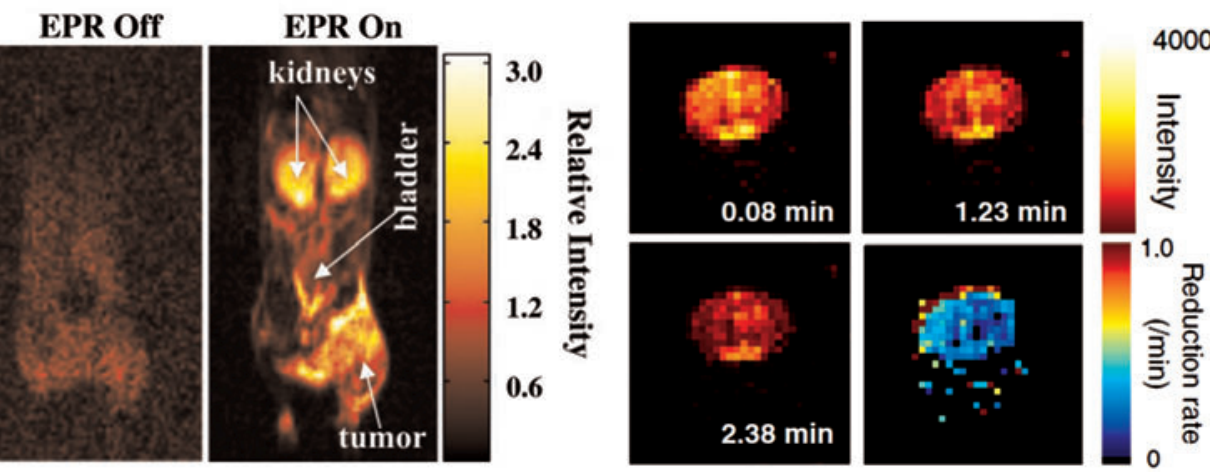

FIG. 10. Left: Interleaved ("EPR off" and "EPR on") OMRI images (coronal) of bearing SCC tumor on the right hind leg, demonstrating the $\mathrm{OE}$ and the diagnostic quality achievable at this low magnetic field of $15 \mathrm{mT}$. The mouse was administered $3.8 \mathrm{mmol} / \mathrm{kg}$ triarymethyl radical by tail vein (72). Right: OMRI images of rat brain microinjected with neurodegenerative changes inducing agent (6-OHDA) into right hemisphere striatum. Redox status assessed 6 weeks later by the time-dependent OMRI signal of i.v.-injected methoxycarbonyl-PROXYL and the processed image showing the reduction rates in two hemispheres, demonstrating diminished reducing compatibilities in affected hemisphere. Adapted from Yamato et al. (147). Reprinted with permission of Elsevier. OE, overhauser enhancement. To see this illustration in color, the reader is referred to the web version of this article at www.liebertpub.com/ars 
protons was performed almost 30 years ago (86) and was referred to as PEDRI (proton electron double resonance imaging). Briefly, the two-spin system (e.g., nitroxide/water protons) in the magnetic field is irradiated by RF at an EPR frequency of nitroxides (unpaired electron); magnetization is transferred to protons enhancing water proton NMR signal intensities; and the overall effect is detected by conventional proton MRI (86). This effect is completely different from classical enhancement of proton relaxation by nitroxides (theoretically 330 times higher). This is illustrated in Figure 10 on MRI of nitroxide-infused mice (72). Without EPR, RF irradiation nitroxides are invisible since classical enhancement is weak, whereas they can be clearly seen in the "EPR on" mode. Some nice examples (Fig. 10B) on the usefulness of this technique in imaging of the brain redox status have been published $(147,148)$. The OMRI combines the sensitivity of EPR with the advantages of MRI, thus presenting an ideal machine for ROS imaging. However, OMRI apparatus has to be home-built, which requires substantial skill and resources. The impetus for further development may come from the fact that in vivo DNP-MRI has an intrinsic capacity for molecular imaging of multiple species, similar to MR chemical shift imaging. By changing the frequency of EPR irradiation in DNP-MRI, distinct images of different radicals having different EPR spectra can be obtained, which has been demonstrated in an experiment where nitroxides labeled with ${ }^{14} \mathrm{~N}$ or ${ }^{15} \mathrm{~N}$ were simultaneously imaged (141). This approach was further extended, although in test tubes, to simultaneous imaging of free radical intermediates involved in the mitochondrial electron transport chain and radicals derived from vitamins $\mathrm{E}$ and $\mathrm{K}_{1}$ (53). Being able to simultaneously image species with a heterogeneous broad line having poor hyperfine splitting or species with complicated hyperfine splitting lines, which is impossible for standard EPRI, opens a host of possibilities, including metabolic imaging in various pathologies and imaging of spin-trapped radicals.

\section{Conclusions}

The relevance of ROS in human physiopathology is now a well-established clinical notion (30). Reactive species are essential regulators in the physiopathology of disease; the knowledge of their concentration and local distribution with subcellular resolution is, therefore, a necessary clinical tool. This can be achieved by using different approaches based on the detection of redox couples, biomarkers that specifically bind to a redox species or that can modify their properties in the presence of ROS or some by-product of the oxidation (Fig. 1). The most investigated solution is the "photonic" one. A wide variety of fluorescent probes and fluorescent NPs in the visible range, specific for each redox couples, allow redox mapping with $200 \mathrm{~nm}$ resolution, according to the Abbe law. Recently, new optical techniques (Stimulated emission-depletion fluorescence microscopy, photoactivated localization microscopy, etc.) $(80,144)$ have been developed to break down the resolution limit up to $20 \mathrm{~nm}$, but specific probes are needed and, at the moment, these are unavailable for redox detection. Instead, the development of redoxsensitive fluorescent probes allowed a quantitative detection of each component of each of the redox couples, representing a further step ahead toward the comprehension of ROS involvement in the human physiopathology.
For these reasons, fluorescence microscopy not only has become very popular in biomedical research activities (i.e., on cell lines) but also has found relevant translation applications in the histopathology of tissues from biopsies and in the investigation of dermal injuries (i.e., melanoma detection) $(109,110)$.

These techniques, however, suffer from two main drawbacks that hampered their potential translational applications: (i) the low penetration of the visible light into tissues (roughly $300 \mathrm{~nm}$ ) due to the tissues' optical absorbance (mainly due to hemoglobin) and multiple scattering, and (ii) the toxicity of fluorescent probes. TPM with endogenous or chemo-selective probes offers an attractive approach to in vivo ROS detection, due to the probes' general compatibility with many biological systems without external activating enzymes and genetic manipulation. TPM for in vivo and internal tissue imaging by using endogenous probes is a very attractive option and has stimulated the development of TPM microendoscopes by using a gradient-index rod lens, miniature compound lens (68, 114). Otherwise, to avoid the low signal-to-noise ratio provided by endogenous or chemo-selective probes, and to increase the penetration depth, the use of TP-excited IR and chemiluminescent probes has been proposed.

Microscopy in the NIR-VIS region of the electromagnetic spectrum is therefore very promising, although it may suffer due to limited clinical applications, when large spatial areas have to be scanned. Indeed, if we are interested in ROS distribution on a large scale (i.e., on the whole organ of a human being), we need different approaches. These can be furnished by intriguing applications of techniques commonly adopted in clinical investigation.

Ultrasound-based techniques, as demonstrated for the APL bio-sensors, allow a detection of physiological concentrations of ROS, with a contrast and a spatial resolution that can exceed those provided by fluorescence and chemiluminescence-based contrast agents. Evaluation is possible on a rapid time-scale (minutes), and imaging systems are in widespread clinical use. However, although toxicity of APLs and MMCs remains a concern, functionalizing these agents allows a selective destruction of target tissues.

Toxicity is a minor feature for PET and SPECT that are noninvasive, but they do involve exposure to ionizing radiation. Besides its established role as a diagnostic technique, PET has an expanding role as a method to assess the response to therapy, in particular, cancer therapy, where the risk to the patient from lack of knowledge about disease progress is much greater than the risk from the test radiation. The principal concern in PET and SPECT redox imaging is the lack of radiolabeled molecules that bind to ROS, and that has limited success of nuclear medicine in the direct imaging of ROS. Nevertheless, indirect methods for imaging of glucose consumption, redox potential, hypoxia, as well as direct imaging of ROS scavengers and mitochondrial complexes have undisputable clinical interest. Considering the sustained efforts in development of new isotopes and labeling methods, PET and SPECT are poised to make significant contributions to the field in the future. Another limitation is the resolution of clinical and preclinical PET cameras (roughly $1 \mathrm{~mm}$ ).

The EPR and MR imaging in vivo has become a powerful tool in experimental and preclinical studies of ROS/RNS or redox status on animals. Basic concepts are well understood, and directions for future developments are clear. On the 
instrumental side, further development of hybrid machines is an obvious goal. The problem remains that these machines are expensive and have to be more or less home-built. On the side of probes and traps, the development of those that show specificity toward certain ROS, specificity toward certain organs (e.g., tumors) and showing longer in vivo life time is required; some studies along these lines are already underway $(1,85,107,113)$. The major obstacle in the translation of these techniques to the clinic is the scarcity of centers possessing the equipment, and the lack of a focused concerted effort on certain clusters of widely relevant pathologies in which ROS may play a key role (e.g., Amyotrophic Lateral Sclerosis, Parkinson, Alzheimer, and other neurodegenarative diseases). Clinical application of EPR spectroscopy has been summarized recently (65), stating that the best perspectives are in oximetry and dosimetry ionizing irradiation. One can add certain potential in investigating skin pathologies, including melanoma, to the list, but, due to problems with penetration depth of microwaves, EPRI of human body analogous to MRI will never be possible. On the other hand, it has been successfully demonstrated that OMRI machines accommodating large subjects, including humans, can be built $(72,87)$, opening possibilities to combine all MRI capabilities with molecular specificity of EPR in diagnosis and treatment follow-up.

\section{Outlook}

Potential clinical translation of ROS imaging is straightforward. Each of the presented techniques possess an attractive potential, but none of them can fulfill all the requirements in terms of sensitivity, spatial resolution, temporal resolution, probe availability, toxicity, and cost. The obvious solution is to perform parallel studies with two or more techniques or even better to integrate imaging modalities that may offer synergistic advantages over any single modality alone. Some hybrid imaging systems such as PET/ CT, SPECT/CT, PET/MRI, and EPR/MRI have already been developed. Anatomical imaging techniques such as CT and MRI provide structural details; whereas functional modalities such as PET, SPECT, TP-fluorescence, EPR, and others provide insight into functional and metabolic aspects. Incorporation of anatomical and functional imaging in a common hybrid imaging platform should allow improved diagnosis, therapeutic planning, and follow-up studies.

\section{Acknowledgments}

This work was supported by the Ministry of Education, Culture, Sports, Science, and Technology, Japan, Japan Science and Technology Agency, KAKENHI (Grant Numbers 22249003, 25253005, and 25713004), Japan Society for the Promotion of Science, Ministry of Education, Science, and Technology, Serbia (project III-41005), and Fondi di Ateneo, UCSC Rome, Italy (Linea D1). Some of the two photon acquisitions and analysis described in the article were performed at LabCeMi, UCSC, Rome. Several authors of this article were supported by the European Cooperation in Science and Technology (COST Action BM1203/EU-ROS).

\section{References}

1. Abbas K, Hardy M, Poulhès F, Karoui H, Tordo P, Ouari $\mathrm{O}$, and Peyrot $\mathrm{F}$. Detection of superoxide production in stimulated and unstimulated living cells using new cyclic nitrone spin traps. Free Radic Biol Med 71: 281-290, 2014.

2. Ahmad R, Caia G, Potter LC, Petryakov S, Kuppusamy P, and Zweier JL. In vivo multisite oximetry using EPRNMR coimaging. J Magn Reson 207: 69-77, 2010.

3. Alecci M, Ferrari M, Quaresima V, Sotgiu A, and Ursini CL. Simultaneous $280 \mathrm{MHz}$ EPR imaging of rat organs during nitroxide free radical clearance. Biophys J 67: 1274 1279, 1994.

4. Bacic G, Nilges MJ, Magin RL, Walczak T, and Swartz HM. In vivo localized ESR spectroscopy reflecting metabolism. Magn Reson Med 10: 266-272, 1989.

5. Ballinger JR. Imaging hypoxia in tumors. Semin Nucl Med 31: 321-329, 2001.

6. Beckman JS, Beckman TW, Chen J, Marshall PA, and Freeman BA. Apparent hydroxyl radical production by peroxynitrite: implications for endothelial injury from nitric oxide and superoxide. Proc Natl Acad Sci U S A 87: 1620-1624, 1990

7. Berliner $\mathbf{J}$ and Fujii $\mathrm{H}$. Magnetic resonance imaging of biological specimens by electron paramagnetic resonance of nitroxide spin labels. Science 227: 517-519, 1985.

8. Berliner L, Khramtsov VV, Clanton T, and Fujii H. NMR and MRI spin trapping: using NMR to learn about free radical reactions. Curr Top Biophys 26: 21:27, 2002.

9. Berliner LJ, Fujii H, Wan XM, and Lukiewicz SJ. Feasibility study of imaging a living murine tumor by electron paramagnetic resonance. Magn Reson Med 4: 380-384, 1987.

10. Berliner LJ (Ed.). In Vivo EPR (ESR). New York: Springer, 2003.

11. Bézière N, Decroos C, Mkhitaryan K, Kish E, Richard F, Bigot-Marchand S, Durand S, Cloppet F, Chauvet C, Corvol M-T, Rannou F, Xu-Li Y, Mansuy D, Peyrot F, and Frapart Y-M. First combined in vivo X-ray tomography and high-resolution molecular electron paramagnetic resonance (EPR) imaging of the mouse knee joint taking into account the disappearance kinetics of the EPR probe. Mol Imaging 11: 220-228, 2012.

12. Björnberg O, Østergaard H, and Winther JR. Mechanistic insight provided by glutaredoxin within a fusion to redoxsensitive yellow fluorescent protein. Biochemistry 45: 2362-2371, 2006.

13. Blankenberg FG, Kinsman SL, Cohen BH, Goris ML, Spicer KM, Perlman SL, Krane EJ, Kheifets V, Thoolen M, Miller G, and Enns GM. Brain uptake of Tc99mHMPAO correlates with clinical response to the novel redox modulating agent EPI-743 in patients with mitochondrial disease. Mol Genet Metab 107: 690-699, 2012.

14. Brasch RC. Work in progress: methods of contrast enhancement for NMR imaging and potential applications. A subject review. Radiology 147: 781-788, 1983.

15. Caia GL, Efimova OV, Velayutham M, El-Mahdy MA, Abdelghany TM, Kesselring E, Petryakov S, Sun Z, Samouilov A, and Zweier JL. Organ specific mapping of in vivo redox state in control and cigarette smokeexposed mice using EPR/NMR co-imaging. J Magn Reson 216: 21-27, 2012.

16. Chan J, Dodani SC, and Chang CJ. Reaction-based smallmolecule fluorescent probes for chemoselective bioimaging. Nat Chem 4: 973-984, 2012.

17. Chen J, Zhuo S, Chen R, Jiang X, Xie S, and Zou Q. Depthresolved spectral imaging of rabbit oesophageal tissue based on two-photon excited fluorescence and secondharmonic generation. New J Phys 9: 212-212, 2007. 
18. Chen R, Zhang L, Gao J, Wu W, Hu Y, and Jiang X. Chemiluminescent nanomicelles for imaging hydrogen peroxide and self-therapy in photodynamic therapy. $J$ Biomed Biotechnol 2011: 679492, 2011.

19. Chung C, Srikun D, Lim CS, Chang CJ, and Cho BR. A two-photon fluorescent probe for ratiometric imaging of hydrogen peroxide in live tissue. Chem Commun 47: 9618-9620, 2011.

20. Cutler RG and Rodriguez H. (Eds.) Critical Reviews of Oxidative Stress and Aging: Advances in Basic Science, Diagnostics and Intervention, Volume 2. Hackensack, NJ: World Scientific Publishing, 2003.

21. D'Autréaux B and Toledano MB. ROS as signalling molecules: mechanisms that generate specificity in ROS homeostasis. Nat Rev Mol Cell Biol 8: 813-824, 2007.

22. Dasari M, Lee D, Erigala VR, and Murthy N. Chemiluminescent PEG-PCL micelles for imaging hydrogen peroxide. J Biomed Mater Res A 89: 561-566, 2009.

23. Davis RM, Sowers AL, DeGraff W, Bernardo M, Thetford A, Krishna MC, and Mitchell JB. A novel nitroxide is an effective brain redox imaging contrast agent and in vivo radioprotector. Free Radic Biol Med 51: 780790, 2011.

24. Dickinson BC, Lin VS, and Chang CJ. Preparation and use of MitoPY1 for imaging hydrogen peroxide in mitochondria of live cells. Nat Protoc 8: 1249-1259, 2013.

25. Dikalov SI, Kirilyuk IA, Voinov M, and Grigor'ev IA. EPR detection of cellular and mitochondrial superoxide using cyclic hydroxylamines. Free Radic Res 45: 417430, 2011.

26. Dobrucki JW, Demsar F, Walczak T, Woods RK, Bacic G, and Swartz HM. Electron spin resonance microscopy of an in vitro tumour model. Br J Cancer 61: 221-224, 1990.

27. Dong X, Heo CH, Chen S, Kim HM, and Liu Z. Quinolinebased two-photon fluorescent probe for nitric oxide in live cells and tissues. Anal Chem 86: 308-311, 2014.

28. Elas M, Ichikawa K, and Halpern HJ. Oxidative stress imaging in live animals with techniques based on electron paramagnetic resonance. Radiat Res 177:514-523, 2012.

29. Ferrari M, Colacicchi S, Gualtieri G, Santini MT, and Sotgiu A. Whole mouse nitroxide free radical pharmacokinetics by low frequency electron paramagnetic resonance. Biochem Biophys Res Commun 166: 168-173, 1990.

30. Finkel T. Oxidant signals and oxidative stress. Curr Opin Cell Biol 15: 247-254, 2003.

31. Fritzberg AR, Lyster DM, and Dolphin DH. 99mTcglutathione: role of reducing agent on renal retention. Int $J$ Nucl Med Biol 5: 87-92, 1978.

32. Fujii H, Aoki M, Haishi T, Itoh K, and Sakata M. Development of an ESR/MR dual-imaging system as a tool to detect bioradicals. Magn Reson Med Sci 5: 17-23, 2006.

33. Fujii H, Itoh K, Pandian RP, Sakata M, Kuppusamy P, and Hirata $\mathrm{H}$. Measuring brain tissue oxygenation under oxidative stress by ESR/MR dual imaging system. Magn Reson Med Sci 6: 83-89, 2007.

34. Fujii H, Sato-Akaba H, Kawanishi K, and Hirata H. Mapping of redox status in a brain-disease mouse model by three-dimensional EPR imaging. Magn Reson Med 65: 295-303, 2011

35. Fujii H, Wan X, Zhong J, Berliner LJ, and Yoshikawa K. In vivo imaging of spin-trapped nitric oxide in rats with septic shock: MRI spin trapping. Magn Reson Med 42: 235-239, 1999.
36. Fujii HG, Sato-Akaba H, Emoto MC, Itoh K, Ishihara Y, and Hirata $\mathrm{H}$. Noninvasive mapping of the redox status in septic mouse by in vivo electron paramagnetic resonance imaging. Magn Reson Imaging 31: 130-138, 2013.

37. Gallez B, Bacic G, Goda F, Jiang J, O’Hara JA, Dunn JF, and Swartz HM. Use of nitroxides for assessing perfusion, oxygenation, and viability of tissues:In vivo EPR and MRI studies. Magn Reson Med 35: 97-106, 1996.

38. Giorgio M, Trinei M, Migliaccio E, and Pelicci PG. Hydrogen peroxide: a metabolic by-product or a common mediator of ageing signals? Nat Rev Mol Cell Biol 8: 722728, 2007.

39. Di Giuseppe S, Placidi G, and Sotgiu A. New experimental apparatus for multimodal resonance imaging: initial EPRI and NMRI experimental results. Phys Med Biol 46: 1003-1016, 2001.

40. Goda F, Bacic G, O'Hara JA, Gallez B, Swartz HM, and Dunn JF. The relationship between partial pressure of oxygen and perfusion in two murine tumors after X-ray irradiation: a combined gadopentetate dimeglumine dynamic magnetic resonance imaging and in vivo electron paramagnetic resonance oximetry study. Cancer Res 56: 3344-3349, 1996.

41. Guo H, Aleyasin H, Dickinson BC, Haskew-Layton RE, and Ratan RR. Recent advances in hydrogen peroxide imaging for biological applications. Cell Biosci 4: 64, 2014.

42. Guzman JN, Sanchez-Padilla J, Wokosin D, Kondapalli J, Ilijic E, Schumacker PT, and Surmeier DJ. Oxidant stress evoked by pacemaking in dopaminergic neurons is attenuated by DJ-1. Nature 468: 696-700, 2010.

43. Halpern HJ, Yu C, Barth E, Peric M, and Rosen GM. In situ detection, by spin trapping, of hydroxyl radical markers produced from ionizing radiation in the tumor of a living mouse. Proc Natl Acad Sci U S A 92: 796-800, 1995.

44. He G, Deng Y, Li H, Kuppusamy P, and Zweier JL. EPR/ NMR co-imaging for anatomic registration of free-radical images. Magn Reson Med 47: 571-578, 2002.

45. He G, Kutala VK, Kuppusamy $\mathrm{P}$, and Zweier JL. In vivo measurement and mapping of skin redox stress induced by ultraviolet light exposure. Free Radic Biol Med 36: 665672, 2004.

46. He G, Samouilov A, Kuppusamy P, and Zweier JL. In vivo EPR imaging of the distribution and metabolism of nitroxide radicals in human skin. J Magn Reson 148: 155164, 2001.

47. Herrling T, Fuchs J, Rehberg J, and Groth N. UV-induced free radicals in the skin detected by ESR spectroscopy and imaging using nitroxides. Free Radic Biol Med 35: 59-67, 2003.

48. Hirayama A, Nagase S, Ueda A, Oteki T, Takada K, Obara $\mathrm{M}$, Inoue $\mathrm{M}$, Yoh $\mathrm{K}$, Hirayama $\mathrm{K}$, and Koyama A. In vivo imaging of oxidative stress in ischemia-reperfusion renal injury using electron paramagnetic resonance. Am J Physiol Renal Physiol 288: F597-F603, 2005.

49. Hirayama A, Ueda A, Oteki T, Nagase S, Aoyagi K, and Koyama A. In vivo imaging of renal redox status during azelnidipine treatment. Hypertens Res 31: 1643-1650, 2008.

50. Hirayama A, Yoh K, Nagase S, Ueda A, Itoh K, Morito N, Hirayama K, Takahashi S, Yamamoto M, and Koyama A. EPR imaging of reducing activity in Nrf2 transcriptional factor-deficient mice. Free Radic Biol Med 34: 1236-1242, 2003. 
51. Hong H, Sun J, and Cai W. Multimodality imaging of nitric oxide and nitric oxide synthases. Free Radic Biol Med 47: 684-698, 2009.

52. Hyodo F, Chuang K-H, Goloshevsky AG, Sulima A, Griffiths GL, Mitchell JB, Koretsky AP, and Krishna MC. Brain redox imaging using blood-brain barrier-permeable nitroxide MRI contrast agent. J Cereb Blood Flow Metab 28: 1165-1174, 2008.

53. Hyodo F, Ito S, Yasukawa K, Kobayashi R, and Utsumi H. Simultaneous and spectroscopic redox molecular imaging of multiple free radical intermediates using dynamic nuclear polarization-magnetic resonance imaging. Anal Chem 86: 7234-7238, 2014.

54. Hyodo F, Matsumoto K-I, Matsumoto A, Mitchell JB, and Krishna MC. Probing the intracellular redox status of tumors with magnetic resonance imaging and redox-sensitive contrast agents. Cancer Res 66: 9921-9928, 2006.

55. Hyodo F, Matsumoto S, Devasahayam N, Dharmaraj C, Subramanian S, Mitchell JB, and Krishna MC. Pulsed EPR imaging of nitroxides in mice. J Magn Reson 197: 181-185, 2009.

56. Hyodo F, Murugesan R, Matsumoto K, Hyodo E, Subramanian S, Mitchell JB, and Krishna MC. Monitoring redox-sensitive paramagnetic contrast agent by EPRI, OMRI and MRI. J Magn Reson 190: 105-112, 2008.

57. Hyodo F, Yasukawa K, Yamada K-I, and Utsumi H. Spatially resolved time-course studies of free radical reactions with an EPRI/MRI fusion technique. Magn Reson Med 56: 938-943, 2006.

58. Ilangovan G, Li H, Zweier JL, Krishna MC, Mitchell JB, and Kuppusamy P. In vivo measurement of regional oxygenation and imaging of redox status in RIF-1 murine tumor: effect of carbogen-breathing. Magn Reson Med 48: 723-730, 2002.

59. Imada I, Sato EF, Miyamoto M, Ichimori Y, Minamiyama Y, Konaka R, and Inoue M. Analysis of reactive oxygen species generated by neutrophils using a chemiluminescence probe L-012. Anal Biochem 271: 53-58, 1999.

60. Ishida S, Matsumoto S, Yokoyama H, Mori N, Kumashiro $\mathrm{H}$, Tsuchihashi N, Ogata T, Yamada M, Ono M, and Kitajima T. An ESR-CT imaging of the head of a living rat receiving an administration of a nitroxide radical. Magn Reson Imaging 10: 109-114, 1992.

61. Jung K-H, Lee JH, Thien Quach CH, Paik J-Y, Oh H, Park JW, Lee EJ, Moon S-H, and Lee K-H. Resveratrol suppresses cancer cell glucose uptake by targeting reactive oxygen species-mediated hypoxia-inducible factor- $1 \alpha$ activation. J Nucl Med 54: 2161-2167, 2013.

62. Kalyanaraman B. Teaching the basics of redox biology to medical and graduate students: oxidants, antioxidants and disease mechanisms. Redox Biol 1: 244-257, 2013.

63. Kelm M. Nitric oxide metabolism and breakdown. Biochim Biophys Acta Bioenerg 1411: 273-289, 1999.

64. Khan N and Swartz H. Measurements in vivo of parameters pertinent to ROS/RNS using EPR spectroscopy. Mol Cell Biochem 234-235: 341-357.

65. Khan N, Williams BB, and Swartz HM. Clinical applications of in vivo EPR: rationale and initial results. Appl Magn Reson 30: 185-199, 2006.

66. Kielland A, Blom T, Nandakumar KS, Holmdahl R, Blomhoff $\mathrm{R}$, and Carlsen $\mathrm{H}$. In vivo imaging of reactive oxygen and nitrogen species in inflammation using the luminescent probe L-012. Free Radic Biol Med 47: 760-766, 2009.
67. Kim D-W, Kim WH, Kim MH, Kim CG, Oh C-S, and Min JJ. Synthesis and evaluation of Tc-99m DTPA-glutathione as a non-invasive tumor imaging agent in a mouse colon cancer model. Ann Nucl Med 28: 447-454, 2014.

68. Kim P, Puoris'haag M, Côté D, Lin CP, and Yun SH. In vivo confocal and multiphoton microendoscopy. $J$ Biomed Opt 13: 010501, 2008.

69. Kobayashi HP, Watanabe T, Oowada S, Hirayama A, Nagase S, Kamibayashi $M$, and Otsubo T. Effect of CV159-Ca(2+)/calmodulin blockade on redox status hepatic ischemia-reperfusion injury in mice evaluated by a newly developed in vivo EPR imaging technique. J Surg Res 147: 41-49, 2008.

70. Koide Y, Kawaguchi M, Urano Y, Hanaoka K, Komatsu T, Abo M, Terai T, and Nagano T. A reversible nearinfrared fluorescence probe for reactive oxygen species based on Te-rhodamine. Chem Commun (Camb) 48: 30913093, 2012.

70a. Koprowski $\mathrm{H}$ and Maeda $\mathrm{H}$ (Eds.). The Role of Nitric Oxide in Physiology and Pathophysiology, Berlin: SpringerVerlag, 1995.

71. Kozlov AV, Szalay L, Umar F, Kropik K, Staniek K, Niedermüller H, Bahrami S, and Nohl H. Skeletal muscles, heart, and lung are the main sources of oxygen radicals in old rats. Biochim Biophys Acta 1740: 382-389, 2005.

72. Krishna MC, English S, Yamada K, Yoo J, Murugesan R, Devasahayam N, Cook JA, Golman K, Ardenkjaer-Larsen JH, Subramanian S, and Mitchell JB. Overhauser enhanced magnetic resonance imaging for tumor oximetry: coregistration of tumor anatomy and tissue oxygen concentration. Proc Natl Acad Sci U S A 99: 2216-2221, 2002.

73. Kuppusamy P, Afeworki M, Shankar RA, Coffin D, Krishna MC, Hahn SM, Mitchell JB, and Zweier JL. In vivo electron paramagnetic resonance imaging of tumor heterogeneity and oxygenation in a murine model. Cancer Res 58: 1562-1568, 1998.

74. Kuppusamy P, Li H, Ilangovan G, Cardounel AJ, Zweier JL, Yamada K, Krishna MC, and Mitchell JB. Noninvasive imaging of tumor redox status and its modification by tissue glutathione levels.

75. Kuppusamy P, Shankar RA, Roubaud VM, and Zweier JL. Whole body detection and imaging of nitric oxide generation in mice following cardiopulmonary arrest: detection of intrinsic nitrosoheme complexes. Magn Reson Med 45: 700707, 2001.

76. Lassen NA, Andersen AR, Friberg L, and Paulson OB. The retention of [99mTc]-d,l-HM-PAO in the human brain after intracarotid bolus injection: a kinetic analysis. J Cereb Blood Flow Metab 8: S13-S22, 1988.

77. Lee D, Khaja S, Velasquez-Castano JC, Dasari M, Sun C, Petros J, Taylor WR, and Murthy N. In vivo imaging of hydrogen peroxide with chemiluminescent nanoparticles. Nat Mater 6: 765-769, 2007.

78. Lee I-J, Hwang O, Yoo D-H, Khang G-S, and Lee D-W. Detection of hydrogen peroxide in vitro and in vivo using peroxalate chemiluminescent micelles. Bull Korean Chem Soc 32: 2187-2192, 2011.

79. Lee JH, Lim CS, Tian YS, Han JH, and Cho BR. A twophoton fluorescent probe for thiols in live cells and tissues. J Am Chem Soc 132: 1216-1217, 2010.

80. Lippincott-Schwartz J, Altan-Bonnet N, and Patterson GH. Photobleaching and photoactivation: following protein dynamics in living cells. Nat Cell Biol Suppl: S7-S14, 2003. 
81. Liu KJ, Bacic G, Jack Hoopes P, Jiang J, Du H, Ou LC, Dunn JF, and Swartz HM. Assessment of cerebral pO2 by EPR oximetry in rodents: effects of anesthesia, ischemia, and breathing gas. Brain Res 685: 91-98, 1995.

82. Liu S, Timmins GS, Shi H, Gasparovic CM, and Liu KJ. Application of in vivo EPR in brain research: monitoring tissue oxygenation, blood flow, and oxidative stress. NMR Biomed 17: 327-334, 2004.

83. Liu WF, Ma M, Bratlie KM, Dang TT, Langer R, and Anderson DG. Real-time in vivo detection of biomaterialinduced reactive oxygen species. Biomaterials 32: 17961801, 2011.

84. Liu Y, Davidson BP, Yue Q, Belcik T, Xie A, Inaba Y, McCarty OJT, Tormoen GW, Zhao Y, Ruggeri ZM, Kaufmann BA, and Lindner JR. Molecular imaging of inflammation and platelet adhesion in advanced atherosclerosis effects of antioxidant therapy with NADPH oxidase inhibition. Circ Cardiovasc Imaging 6: 74-82, 2013.

85. Liu Y, Song Y, De Pascali F, Liu X, Villamena FA, and Zweier JL. Tetrathiatriarylmethyl radical with a single aromatic hydrogen as a highly sensitive and specific superoxide probe. Free Radic Biol Med 53: 2081-2091, 2012.

86. Lurie DJ, Bussell DM, Bell LH, and Mallard JR. Protonelectron double magnetic resonance imaging of free radical solutions. J Magn Reson 76: 366-370, 1988.

87. Lurie DJ, Foster MA, Yeung D, and Hutchison JM. Design, construction and use of a large-sample field-cycled PEDRI imager. Phys Med Biol 43: 1877-1886, 1998.

88. Maghzal GJ, Cergol KM, Shengule SR, Suarna C, Newington D, Kettle AJ, Payne RJ, and Stocker R. Assessment of myeloperoxidase activity by the conversion of hydroethidine to 2-chloroethidium. J Biol Chem 289: 55805595, 2014.

89. Maly T, Debelouchina GT, Bajaj VS, Hu K-N, Joo C-G, Mak-Jurkauskas ML, Sirigiri JR, van der Wel PCA, Herzfeld J, Temkin RJ, and Griffin RG. Dynamic nuclear polarization at high magnetic fields. J Chem Phys 128: 052211, 2008.

90. Matsumoto K, Subramanian S, Murugesan R, Mitchell JB, and Krishna MC. Spatially resolved biologic information from in vivo EPRI, OMRI, and MRI. Antioxid Redox Signal 9: 1125-1141, 2007.

90a. Maulucci G, Chiarpotto M, Papi M, Samengo D, Pani G, and De Spirito M. Quantitative analysis of autophagic flux by confocal $\mathrm{pH}$-imaging of autophagic intermediates. Autophagy 11: 1905-1916, 2015.

91. Maulucci G, Labate V, Mele M, Panieri E, Arcovito G, Galeotti T, Østergaard H, Winther JR, De Spirito M, and Pani G. High-resolution imaging of redox signaling in live cells through an oxidation-sensitive yellow fluorescent protein. Sci Signal 1: pl3, 2008.

92. Maulucci G, Labate V, Mele M, Panieri E, Arcovito G, Galeotti T, Østergaard H, Winther JR, De Spirito M, and Pani G. High-resolution imaging of redox signaling in live cells through an oxidation-sensitive yellow fluorescent protein. Sci Signal 1: pl3, 2008.

93. Maulucci G, Pani G, Fusco S, Papi M, Arcovito G, Galeotti T, Fraziano M, and De Spirito M. Compartmentalization of the redox environment in PC-12 neuronal cells. Eur Biophys J 39: 993-999, 2010.

94. Maulucci G, Pani G, Labate V, Mele M, Panieri E, Papi M, Arcovito G, Galeotti T, and De Spirito M. Investiga- tion of the spatial distribution of glutathione redoxbalance in live cells by using Fluorescence Ratio Imaging Microscopy. Biosens Bioelectron 25: 682-687, 2009.

95. Maulucci G, Pani G, Papi M, and Galeotti T. Can redoxsensitive fluorescent probes measure intracellular redox potentials? Nuovo Cim 125: 645-655, 2010.

96. Maulucci G, Troiani D, Eramo SLM, Paciello F, Podda MV, Paludetti G, Papi M, Maiorana A, Palmieri V, De Spirito M, and Fetoni AR. Time evolution of noise induced oxidation in outer hair cells: role of NAD(P)H and plasma membrane fluidity. Biochim Biophys Acta 1840: 2192-2202, 2014.

97. This reference has been deleted.

98. Mikuni T, He G, Petryakov S, Fallouh MM, Deng Y, Ishihara R, Kuppusamy $\mathrm{P}$, Tatsuta $\mathrm{M}$, and Zweier JL. In vivo detection of gastric cancer in rats by electron paramagnetic resonance imaging. Cancer Res 64: 64956502, 2004.

99. Mosconi L, Pupi A, and De Leon MJ. Brain glucose hypometabolism and oxidative stress in preclinical Alzheimer's disease. Ann N Y Acad Sci 1147: 180-195, 2008.

100. Nagano $\mathrm{T}$ and Yoshimura T. Bioimaging of nitric oxide. Chem Rev 102: 1235-1270, 2002.

101. Neirinckx RD, Burke JF, Harrison RC, Forster AM, Andersen $\mathrm{AR}$, and Lassen NA. The retention mechanism of technetium99m-HM-PAO: intracellular reaction with glutathione. $J$ Cereb Blood Flow Metab 8: S4-S12, 1988.

102. Nunn A, Linder K, and Strauss HW. Nitroimidazoles and imaging hypoxia. Eur J Nucl Med 22: 265-280, 1995.

103. O’Donoghue JA, Guillem JG, Schöder H, Lee NY, Divgi CR, Ruby JA, Humm JL, Lee-Kong SA, Burnazi EM, Cai $\mathrm{S}$, Carlin SD, Leibold T, Zanzonico PB, and Ling CC. Pilot study of PET imaging of 124I-iodoazomycin galactopyranoside (IAZGP), a putative hypoxia imaging agent, in patients with colorectal cancer and head and neck cancer. EJNMMI Res 3: 42, 2013.

104. Olson ES, Orozco J, Wu Z, Malone CD, Yi B, Gao W, Eghtedari M, Wang J, and Mattrey RF. Toward in vivo detection of hydrogen peroxide with ultrasound molecular imaging. Biomaterials 34: 8918-8924, 2013.

105. Oushiki D, Kojima H, Terai T, Arita M, Hanaoka K, Urano Y, and Nagano T. Development and application of a near-infrared fluorescence probe for oxidative stress based on differential reactivity of linked cyanine dyes. $J$ Am Chem Soc 132: 2795-2801, 2010.

106. Pacher P, Beckman JS, and Liaudet L. Nitric oxide and peroxynitrite in health and disease. Physiol Rev 87: 315424, 2007.

107. Paletta JT, Pink M, Foley B, Rajca S, and Rajca A. Synthesis and reduction kinetics of sterically shielded pyrrolidine nitroxides. Org Lett 14: 5322-5325, 2012.

108. Perng JK, Lee S, Kundu K, Caskey CF, Knight SF, Satir S, Ferrara KW, Taylor WR, Degertekin FL, Sorescu D, and Murthy N. Ultrasound imaging of oxidative stress in vivo with chemically-generated gas microbubbles. Ann Biomed Eng 40: 2059-2068, 2012.

109. Perry SW, Burke RM, and Brown EB. Two-photon and second harmonic microscopy in clinical and translational cancer research. Ann Biomed Eng 40: 277-291, 2012.

110. Piwnica-Worms D, Chiu ML, Budding M, Kronauge JF, Kramer RA, and Croop JM. Functional Imaging of Multidrugresistant P-Glycoprotein with an Organotechnetium Complex. Cancer Res 53: 977-984, 1993. 
111. Quaresima V, Alecci M, Ferrari M, and Sotgiu A. Whole rat electron paramagnetic resonance imaging of a nitroxide free radical by a radio frequency $(280 \mathrm{MHz})$ spectrometer. Biochem Biophys Res Commun 183: 829-835, 1992.

112. Rassaf T, Preik M, Kleinbongard P, Lauer T, Heiss C, Strauer B-E, Feelisch M, and Kelm M. Evidence for in vivo transport of bioactive nitric oxide in human plasma. J Clin Invest 109: 1241-1248, 2002.

113. Redler G, Barth ED, Bauer KS, Kao JPY, Rosen GM, and Halpern HJ. In vivo electron paramagnetic resonance imaging of differential tumor targeting using cis-3,4-di(acetoxymethoxycarbonyl)-2,2,5,5-tetramethyl-1pyrrolidinyloxyl. Magn Reson Med 71: 1650-1656, 2014.

114. Rivera DR, Brown CM, Ouzounov DG, Pavlova I, Kobat $\mathrm{D}$, Webb WW, and Xu C. Compact and flexible raster scanning multiphoton endoscope capable of imaging unstained tissue. Proc Natl Acad Sci U S A 108: 1759817603, 2011.

115. Ryvolova M, Chomoucka J, Drbohlavova J, Kopel P, Babula P, Hynek D, Adam V, Eckschlager T, Hubalek J, Stiborova M, Kaiser J, and Kizek R. Modern micro and nanoparticle-based imaging techniques. Sensors (Basel) 12: 14792-14820, 2012.

116. Samouilov A, Caia GL, Kesselring E, Petryakov S, Wasowicz T, and Zweier JL. Development of a hybrid EPR/NMR coimaging system. Magn Reson Med 58: 156166, 2007.

117. Sano H, Matsumoto K, and Utsumi H. Synthesis and imaging of blood-brain-barrier permeable nitroxyl-probes for free radical reactions in brain of living mice. Biochem Mol Biol Int 42: 641-647, 1997.

118. Sano H, Naruse M, Matsumoto K, Oi T, and Utsumi H. A new nitroxyl-probe with high retention in the brain and its application for brain imaging. Free Radic Biol Med 28: 959-969, 2000.

119. Santra S, Xu J, Wang K, and Tan W. Luminescent nanoparticle probes for bioimaging. J Nanosci Nanotechnol 4: 590-599, 2004.

120. Sasaki T, Matuoka N, Kubodera A, Ishii S, Goto G, and Senda M. Synthesis of [11C] coenzyme Q-related compounds for in vivo estimation of mitochondrial electron transduction and redox state in brain. Nucl Med Biol 26: 183-187, 1999.

121. Sasaki T, Senda M, Kim S, Kojima S, and Kubodera A. Age-related changes of glutathione content, glucose transport and metabolism, and mitochondrial electron transfer function in mouse brain. Nucl Med Biol 28: 2531, 2001.

122. Sato M, Hida N, and Umezawa Y. Imaging the nanomolar range of nitric oxide with an amplifier-coupled fluorescent indicator in living cells. Proc Natl Acad Sci U S A 102: 14515-14520, 2005.

123. Schwarzländer M, Fricker MD, Müller C, Marty L, Brach T, Novak J, Sweetlove LJ, Hell R, and Meyer AJ. Confocal imaging of glutathione redox potential in living plant cells. J Microsc 231: 299-316, 2008.

124. Shuttleworth CW. Use of $\mathrm{NAD}(\mathrm{P}) \mathrm{H}$ and flavoprotein autofluorescence transients to probe neuron and astrocyte responses to synaptic activation. Neurochem Int 56: 379-386, 2010.

125. Skala $\mathrm{M}$ and Ramanujam N. Multiphoton redox ratio imaging for metabolic monitoring in vivo. Methods Mol Biol 594: 155-162, 2010.
126. Skala MC, Riching KM, Gendron-Fitzpatrick A, Eickhoff $\mathrm{J}$, Eliceiri $\mathrm{KW}$, White $\mathrm{JG}$, and Ramanujam N. In vivo multiphoton microscopy of NADH and FAD redox states, fluorescence lifetimes, and cellular morphology in precancerous epithelia. Proc Natl Acad Sci U S A 104: 1949419499, 2007.

127. Skala MC, Squirrell JM, Vrotsos KM, Eickhoff JC, Gendron-Fitzpatrick A, Eliceiri KW, and Ramanujam N. Multiphoton microscopy of endogenous fluorescence differentiates normal, precancerous, and cancerous squamous epithelial tissues. Cancer Res 65: 1180-1186, 2005.

128. Sonta T, Inoguchi T, Matsumoto S, Yasukawa K, Inuo M, Tsubouchi H, Sonoda N, Kobayashi K, Utsumi H, and Nawata H. In vivo imaging of oxidative stress in the kidney of diabetic mice and its normalization by angiotensin II type 1 receptor blocker. Biochem Biophys Res Commun 330: 415-422, 2005.

129. Stringari C, Cinquin A, Cinquin O, Digman MA, Donovan PJ, and Gratton E. Phasor approach to fluorescence lifetime microscopy distinguishes different metabolic states of germ cells in a live tissue. 108: 13582-13587, 2011.

130. Stringari C, Edwards RA, Pate KT, Waterman ML, Donovan PJ, and Gratton E. Metabolic trajectory of cellular differentiation in small intestine by Phasor Fluorescence Lifetime Microscopy of NADH. Sci Rep 2: 568, 2012.

131. Swartz HM. Use of nitroxides to measure redox metabolism in cells and tissues. J Chem Soc Faraday Trans 1 Phys Chem Condens Phases 83: 191, 1987.

132. Takeshita K, Kawaguchi K, Fujii-Aikawa K, Ueno M, Okazaki S, Ono M, Krishna MC, Kuppusamy P, Ozawa T, and Ikota N. Heterogeneity of regional redox status and relation of the redox status to oxygenation in a tumor model, evaluated using electron paramagnetic resonance imaging. Cancer Res 70: 4133-4140, 2010.

133. Takeshita K, Utsumi H, and Hamada A. ESR measurement of radical clearance in lung of whole mouse. Biochem Biophys Res Commun 177: 874-880, 1991.

134. Timmins GS, Liu KJ, Bechara EJ., Kotake Y, and Swartz HM. Trapping of free radicals with direct in vivo EPR detection: a comparison of 5,5-dimethyl-1-pyrroline-Noxide and 5-diethoxyphosphoryl-5-methyl-1-pyrroline-Noxide as spin traps for $\mathrm{HO}$ and SO4•-. Free Radic Biol Med 27: 329-333, 1999.

135. Togashi H, Shinzawa H, Ogata T, Matsuo T, Ohno S, Saito K, Yamada N, Yokoyama H, Noda H, Oikawa K, Kamada H, and Takahashi T. Spatiotemporal measurement of free radical elimination in the abdomen using an in vivo ESR-CT imaging system. Free Radic Biol Med 25: 1-8, 1998.

136. Towner RA, Smith N, Saunders D, Lupu F, Silasi-Mansat R, West M, Ramirez DC, Gomez-Mejiba SE, Bonini MG, Mason RP, Ehrenshaft M, and Hensley K. In vivo detection of free radicals using molecular MRI and immunospin trapping in a mouse model for amyotrophic lateral sclerosis. Free Radic Biol Med 63: 351-360, 2013.

137. Tsien RY and Poenie M. Fluorescence ratio imaging: a new window into intracellular ionic signaling. Trends Biochem Sci 11: 450-455, 1986.

138. Tsukada H, Nishiyama S, Fukumoto D, Kanazawa M, and Harada N. Novel PET probes 18F-BCPP-EF and 18FBCPP-BF for mitochondrial complex I: a PET study in 
comparison with 18F-BMS-747158-02 in rat brain. $J$ Nucl Med 55: 473-480, 2014.

139. Tsukada H, Ohba H, Kanazawa M, Kakiuchi T, and Harada N. Evaluation of 18F-BCPP-EF for mitochondrial complex 1 imaging in the brain of conscious monkeys using PET. Eur $J$ Nucl Med Mol Imaging 41: 755-763, 2014.

140. Utsumi H, Sano H, Naruse M, Matsumoto K, Ichikawa K, and Oi T. Nitroxyl probes for brain research and their application to brain imaging. Methods Enzymol 352: 494506, 2002.

141. Utsumi H, Yamada K, Ichikawa K, Sakai K, Kinoshita Y, Matsumoto S, and Nagai M. Simultaneous molecular imaging of redox reactions monitored by Overhauserenhanced MRI with $14 \mathrm{~N}$ - and 15N-labeled nitroxyl radicals. Proc Natl Acad Sci U S A 103: 1463-1468, 2006.

142. Uusitalo LM and Hempel N. Recent Advances in intracellular and in vivo ROS sensing: focus on nanoparticle and nanotube applications. Int J Mol Sci 13: 1066010679, 2012.

143. Wallrabe $\mathrm{H}$ and Periasamy A. Imaging protein molecules using FRET and FLIM microscopy. Curr Opin Biotechnol 16: 19-27, 2005.

144. Willig KI, Rizzoli SO, Westphal V, Jahn R, and Hell SW. STED microscopy reveals that synaptotagmin remains clustered after synaptic vesicle exocytosis. Nature 440: 935939, 2006.

145. Wolf AM, Nishimaki K, Kamimura N, and Ohta S. Realtime monitoring of oxidative stress in live mouse skin. J Invest Dermatol 134: 1701-1709, 2014.

146. Yamada K-I, Kuppusamy P, English S, Yoo J, Irie A, Subramanian S, Mitchell JB, and Krishna MC. Feasibility and assessment of non-invasive in vivo redox status using electron paramagnetic resonance imaging. Acta Radiol 43: 433-440, 2002.

147. Yamato M, Shiba T, Naganuma T, Ichikawa K, Utsumi H, and Yamada K. Overhauser-enhanced magnetic resonance imaging characterization of mitochondria functional changes in the 6-hydroxydopamine rat model. Neurochem Int 59: 804-811, 2011.

148. Yamato M, Shiba T, Yamada K, Watanabe T, and Utsumi H. Noninvasive assessment of the brain redox status after transient middle cerebral artery occlusion using Overhauserenhanced magnetic resonance imaging. J Cereb Blood Flow Metab 29: 1655-1664, 2009.

149. Yokoyama H, Ishida S-I, and Ogata T. In vivo temporal EPR study using a region-selected intensity determination method to estimate cerebral reducing ability in rats treated with olanzapine. Magn Reson Imaging 28: 898902, 2010.

150. Yokoyama H, Itoh O, Aoyama M, Obara H, Ohya H, and Kamada H. In vivo EPR imaging by using an acylprotected hydroxylamine to analyze intracerebral oxidative stress in rats after epileptic seizures. Magn Reson Imaging 18: 875-879, 2000.

151. Yokoyama H, Itoh O, Aoyama M, Obara H, Ohya H, and Kamada H. In vivo temporal EPR imaging of the brain of rats by using two types of blood-brain barrier-permeable nitroxide radicals. Magn Reson Imaging 20: 277-284, 2002.

152. Yokoyama H, Itoh O, Ohya-Nishiguchi H, and Kamada H. Reducing ability of the striatum and cerebral cortex in rats following acute administration of risperidone or haloperidol: an estimation by in vivo electron paramag- netic resonance imaging. Neurochem Res 27: 243-248, 2002.

153. Yokoyama H, Lin $Y$, Itoh O, Ueda Y, Nakajima A, Ogata T, Sato T, Ohya-Nishiguchi H, and Kamada H. EPR imaging for in vivo analysis of the half-life of a nitroxide radical in the hippocampus and cerebral cortex of rats after epileptic seizures. Free Radic Biol Med 27: 442-448, 1999.

154. Yokoyama H, Morinobu S, and Ueda Y. EPRI to estimate the in vivo intracerebral reducing ability in adolescent rats subjected to neonatal isolation. J Magn Reson Imaging 23: 637-640, 2006.

155. Yokoyama H, Sato T, Oteki T, Ohya H, and Akatsuka T. Estimation of the in vivo decay rate of EPR signals for a nitroxide radical in rat brains by a region-selected intensity determination method. Appl Magn Reson 29: 363 373, 2005.

156. Zhelev Z, Gadjeva V, Aoki I, Bakalova R, and Saga T. Cell-penetrating nitroxides as molecular sensors for imaging of cancer in vivo, based on tissue redox activity. Mol Biosyst 8: 2733-2740, 2012.

157. Zhou J, Tsai Y-T, Weng H, and Tang L. Noninvasive assessment of localized inflammatory responses. Free Radic Biol Med 52: 218-226, 2012.

158. This reference has been deleted.

Address correspondence to:

Prof. Marco De Spirito

Faculty of Medicine and Surgery Institute of Physics

Catholic University of Sacred Hearth L.go F. Vito 1 Roma 00168 Italy

E-mail: marco.despirito@unicatt.it

Date of first submission to ARS Central, July 1, 2015; date of final revised submission, May 2, 2016; date of acceptance, May 2, 2016.

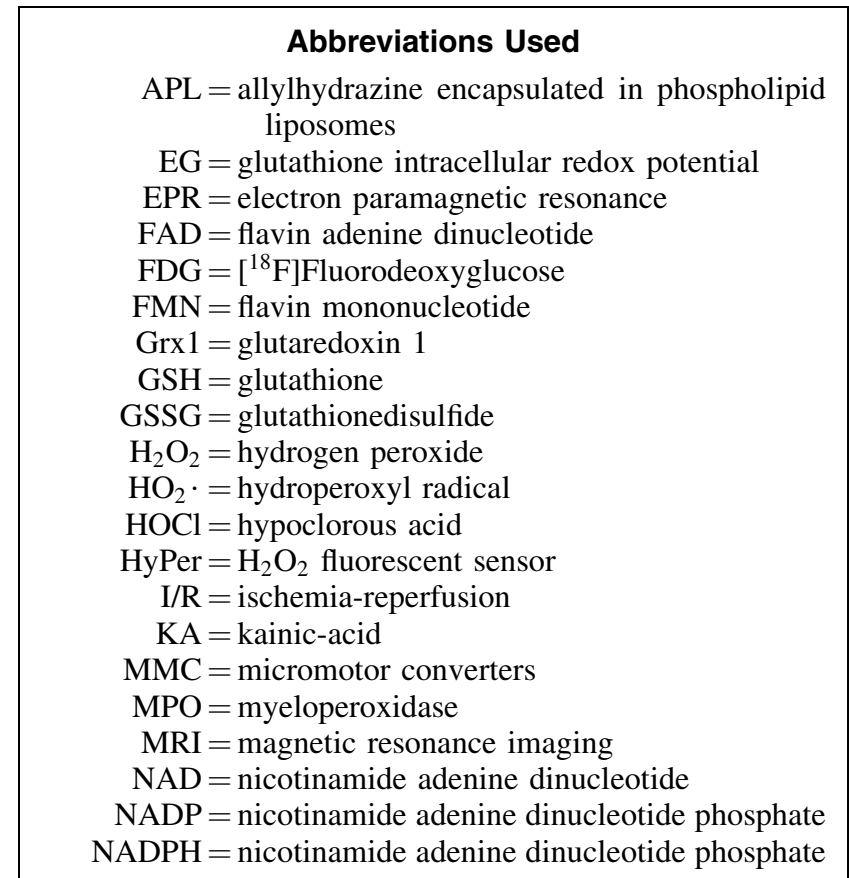




$\begin{aligned} & \quad \text { Abbreviations Used } \\ & \mathrm{NIR}=\text { near-infrared } \\ & \mathrm{NO}=\text { nitric oxide } \\ & \mathrm{NOS}=\text { nitric oxide synthase } \\ & \mathrm{NOX}=\text { NADPH oxidase } \\ & \mathrm{NP}=\text { nanoparticles } \\ & \mathrm{O}_{2}^{\bullet-}=\text { superoxide radical } \\ & \mathrm{ONO}^{-}=\text {peroxynitrite radical } \\ & \mathrm{PEDRI}=\text { proton electron double resonance imaging } \\ & \mathrm{PET}=\text { positron emission tomography } \\ & \mathrm{PN} 1=\text { peroxy naphthalene } 1 \\ & \mathrm{PROXYL}=2,2,5,5 \text {-tetramethylpyrrolidine 1-oxyl } \\ &\end{aligned}$

$\begin{aligned} \mathrm{RNS}= & \text { reactive nitrogen species } \\ \text { roGFP }= & \text { GSH-sensitive green fluorescent protein } \\ \mathrm{ROS}= & \text { reactive oxygen species } \\ \text { rxYFP }= & \text { GSH-sensitive yellow fluorescent protein } \\ \mathrm{SHG}= & \text { second harmonic generation } \\ \mathrm{SPECT}= & \text { single-photon emission computed } \\ & \text { tomography } \\ \mathrm{TEMPO}= & 2,2,6,6 \text {-tetramethylpiperidine } 1 \text {-oxyl } \\ \mathrm{TP}-\mathrm{FLIM}= & \text { two-photon fluorescence lifetime } \\ & \text { imaging microscopy } \\ \mathrm{TP}-\mathrm{FRIM}= & \text { two-photon fluorescence ratio } \\ & \text { imaging microscopy } \\ \mathrm{TPM}= & \text { two-photon microscopy }\end{aligned}$

